\begin{tabular}{|c|c|}
\hline PORT SAID ENGINEERING RESEARCH JOURNAL \\
Faculty of Engineering - Port Said University \\
Volume 22 No. 1 March 2018 pp: $1: 16$
\end{tabular}

\title{
Indoor environmental quality and Sick Building Syndrome in office buildings
}

\author{
Osama Mahmoud Abu Eleinen ${ }^{1}$, Ghada Mohamed Elries ${ }^{2}$ and Marwa Mohamed Elnahas ${ }^{3}$
}

\begin{abstract}
In the last decades public health problems caused by indoor air pollution, such as Sick Building Syndrome (SBS), have been drawing strong public concerns. This study aims at investigating the indoor environment quality (IEQ) and people's complaints in office buildings in Egypt. Indoor environment parameters including air temperature, relative humidity, air speed, TVOC, formaldehyde, Benzene, and Toluene were measured at two office buildings, which located in Giza, and Port Said. The study was done during March 2017-May 2017. Occupants' perception on indoor environmental quality (IEQ), and SBS symptoms were surveyed by questionnaire.

High TVOCs concentration, should be of health effect concern. It was indicated that indoor air quality (IAQ) may lead to SBS symptoms in office building in Egypt.
\end{abstract}

Keywords: Evaluation, Sick Building Syndrome (SBS), Indoor Environmental Quality (IEQ), Indoor Air Quality (IAQ), Volatile Organic Compounds (VOCs), Formaldehyde, Benzene, Toluene.

\section{INTRODUCTION}

Since the seventies and also the oil crisis, energysaving measures have reduced rooms' ventilation rates Circulation of air in an office building was reduced by 80th, the energy efficiency standards and materials used by architects and designers changed dramatically. The use of synthetic materials that emit numerous chemical substances has raised the concentration of indoor pollutants. With poor circulation, this virtually left the door wide open to the various pollutants, bacteria, mold, and mildew that we tend to struggle with daily (Rostron 2005).

The term "sick building syndrome", was initially coined in the Seventies and is used to describe situations in which building occupants expertise acute health and comfort effects that seem to be linked to time spent during a building, however, no specific sickness or cause are often known. The complaints could also be localized in a particular space or zone or could also be widespread throughout the building. Otherwise, the term "building related illness" (BRI) is used to describe symptoms that occur as a result of diagnosable or known illness and might be related to airborne contaminants within the building (Heimlich 2003).

A 1984 World Health Organization Committee report suggested that up to half-hour of new and remodeled buildings worldwide could also be the subject of excessive complaints associated with indoor air quality (IAQ). Usually this condition is temporary, however, some buildings have long-term problems. Generally, complaints appear when a building is operated for another purpose or maintained differently with its original design or prescribed in operating procedures. Generally, indoor air issues are results of poor building design or occupant activities (Spengler, Samet et al. 2001).

In most cases, sick building syndrome occurs in certain types of buildings specifically that heated and ventilated mechanically and in other communal buildings like hospitals, schools, educational institutes, and residential buildings (Claude MOLINA 1989).

Most experts believe that the symptoms of SBS results of a mix of factors including Building factors, Environmental factors, and personal factors, all of those factors create many symptoms making building occupants complain of a headache, dizziness, burning eyes, and upper respiratory. Reaction to indoor pollutants sometimes happens one to two hours after they arrive in the building and last three to four hours after they leave it (Spengler, Samet et al. 2001).

The main goal of the study is to explore sick building syndrome complaints and also the correlation between SBS occurrence and poor indoor environmental quality. The objectives of this study are to (i) investigate occupants for the SBS questionnaire (ii) examine IAQ obtained at IA-QUEST tool by assessing four groups of contaminants: VOCs, Formaldehyde, Benzene, and Toluene; (ii) associate these contaminants with emission sources in the internal environment such as air flow rates and construction materials. These objectives could be achieved by IEQ evaluation on Oracle office building as HVAC ventilation system located in Giza that considered hot-dry climate, and chamber of commerce building in Port Said as a mixed-ventilation system in hot- humid zone.

\footnotetext{
${ }^{1}$ Associate Professor of Architecture and Urban Planning Department Faculty of Engineering - Port Said University

${ }^{2}$ Lecturer of Architecture and Urban Planning Department Faculty of Engineering - Port Said University

3 BSC of architecture and urban planning - Port Said university
} 


\section{MATERIALS AND METHODS:}

\subsection{Study design:}

The study was conducted at two buildings, the first in the smart village, which locate north-west of Giza, Egypt. The selected building is Oracle Office Building (B3), and the second building at Port Said town, which locates north of Egypt, and the selected building is Port Said Chamber of Commerce (PCC). The criteria of buildings selection are based on climate zone, as smart village hot-dry, and Port Said hot-humid. Oracle building, and PCC building located in medium town, near heavy traffic.

\subsection{Questionnaire and samples:}

The study was occurred by two steps. The first step was an initial investigation that divided to three investigations, the first one was the walkthrough checklist was divided into three parts, the first part collected a general information about the building like its age, type, construction date, and renovation, the second part includes occupants' information like their number in the study space. Finally, the third part includes observations about the indoor environmental conditions like ventilation method, materials, cleaning procedures, lighting and noise conditions. the second investigation was a technical questionnaire that answered by the mechanical engineers who are responsible for building maintenance, The questions in this investigation included all information about the HVAC system like the control system, boilers, cooling towers, chillers, and air handling unit. The third was occupant's questionnaires that contain the symptoms of SBS and its causes factors related to the occupants. The questionnaire was divided into four parts. The first part collected a respondent's general information like age, gender, job position, work hours per day, and health status. The second part asked the respondent to report SBS symptoms they experienced while they were staying at the building. In many SBS studies, symptoms included discomfort or problems related to the eyes, nose, throat, head, skin, and fatigue. Respondents were required to answer "often", "sometimes" or "never". The respondents were defined as having SBS if they had at least one symptom of SBS and the symptoms appeared at least once a week. The respondents also must have reported the occurrence of at least 1:3 days per week during the last four weeks and must have reported that the symptoms showed improvement when they were away from the place of work. The third part asked the percentage of occupant satisfaction of indoor environmental conditions, the last part asked about psychological factors and percentage of job satisfaction.

\subsection{Indoor Air Quality Assessment:}

The assessment of IAQ of the selected two buildings conducted by researcher according to the following points:

1.Building profile implies building location, area, year of construction, climate zone, type, and description.

2.Building design and construction process to achieve good IAQ:
-Ventilation principles including method, building orientation, form, the design of openings, Ventilation effectiveness,

-Control Moisture in Building Control liquid water, Select Suitable Materials,

-Indoor pollutant remove, Air filtration,

-Indoor pollutant control Limit and control Entry of Outdoor Contaminants, Control building pressure, air contaminants

3.Thermal comfort: Design, controllability, Verification,

4.Lighting: daylight, artificial lighting.

5.Materials: paints and coating, flooring, furniture, adhesive, exterior materials, and construction.

6.Acoustics insulation.

The numbers of sampling point determined based on the influence factors effect on SBS, and results of a questionnaire survey of buildings' occupant. Measurement of IAQ conducted using simulation programs in Oracle building in March 2017, and in Port Said Chamber of Commerce building in March 2017 and May 2017. The simulation tool used to assess IAQ is IAQuest.

(IA-QUEST) tool is an indoor air quality and emission simulation tool. It is developed by National Research Council Canada to help building designers, engineers and managers assess the impact of the volatile organic compound (VOC) emissions from building materials/furnishings on the indoor air quality in buildings IA-QUEST is a computer program to calculate the concentrations of contaminants that would occur in a ventilated indoor space due to emissions from materials contained within that space. The calculation of concentrations assumes a simple single-zone mixing model. The emission characteristics of materials are obtained from the database packaged with the program. These emission characteristics are derived from laboratory tests of materials. (At this time, this database is very limited both in the number of materials and in the number of contaminants considered for each material.)

The output of the program is a plot of contaminant concentrations vs. time.

The following information is required for this calculation (inputs):

- Volume of the space

- Ventilation rate as a profile vs. time

- Type and amount of materials that are in the space

- Emission characteristics for each material

\section{HYPOTHESIS AND TARGET}

Simulation target is enhancing the flow rates and concentration of indoor contaminants emitted from materials in office halls. So, the study hypothesis is as follows:

"indoor air quality problems by chemicals emitted from building materials may affect by negative or inadequate ventilation rates and causes sick building syndrome and occupants discomfort within the workspace of the building", 


\section{RESUlts:}

\subsection{Building characteristics:}

The characteristics of each building were investigated. The B3 building is newer than PCC building. Both buildings are located in Egypt, near heavy traffic and moderately near industrial area. They were built of concrete or bricks, B3 was glazed-envelope, but PCC's exterior walls coated by marble. Fiberglass or rock wool were not presented within the rooms of any building. All buildings are equipped with mechanical ventilation air conditioning systems. A general smoking is not allowed in these buildings. The cleaning procedures included daily mopping with water which contains detergent. the $\mathrm{B} 3$ and the PCC building was recently undergoing a major renovation, B3's renovation was for interior finishing, while PCC's renovation was with upgrading the ventilation systems due to the water leakage problem.

Oracle building (B3) is one of smart village buildings that locate in the north-west of Giza, it was established in 2001.

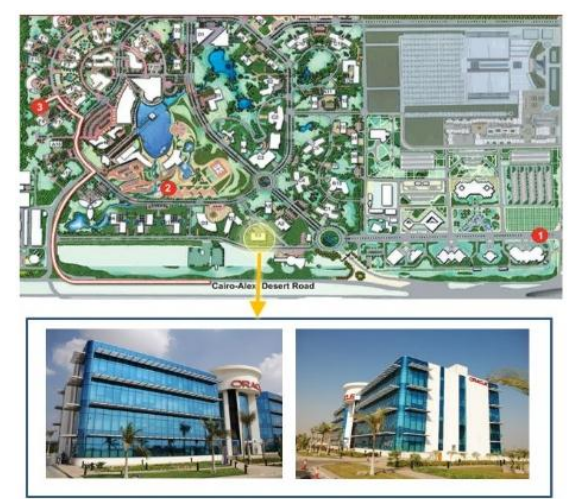

Figure 1: oracle building location.

Port Said Chamber of Commerce is one of governmental buildings located in Port Said. Port Said is a city that lies in north east Egypt extending along the coast of the Mediterranean Sea, north of the Suez Canal.

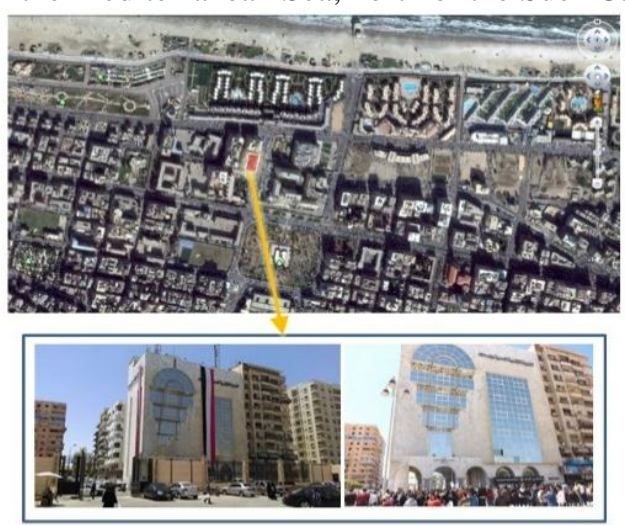

Figure 2: port said chamber of commerce location

\subsection{Selected Zones specification:}

Three zones were selected in the each building for the study, the six Zones are office halls, the selected zones' specification for the study are shown in Table 1, and figures below.
Table 1: The priority of every category in the two

\begin{tabular}{|l|c|c|c|c|c|c|}
\hline \multicolumn{1}{|c|}{$\begin{array}{c}\text { specifi } \\
\text { cations }\end{array}$} & $\mathbf{Z}$ B3 & $\mathbf{Z 2}$ & $\mathbf{Z 3}$ & $\mathbf{Z 1}$ & $\mathbf{Z 2}$ & $\mathbf{Z 3}$ \\
\hline ID & Z1-B3 & Z2-B3 & Z3-B3 & Z1-PCC & Z2- PCC & Z3- PCC \\
\hline Floor & $\begin{array}{c}\text { Ground } \\
\text { floor }\end{array}$ & $\begin{array}{c}\text { first } \\
\text { floor }\end{array}$ & $\begin{array}{c}\text { first } \\
\text { floor }\end{array}$ & first floor & $\begin{array}{c}\text { second } \\
\text { floor }\end{array}$ & $\begin{array}{c}\text { second } \\
\text { floor }\end{array}$ \\
\hline $\begin{array}{l}\text { locatio } \\
\text { n }\end{array}$ & $\begin{array}{c}\text { Right } \\
\text { wing }\end{array}$ & $\begin{array}{c}\text { Right } \\
\text { wing }\end{array}$ & $\begin{array}{c}\text { left } \\
\text { wing }\end{array}$ & - & - & - \\
\hline $\begin{array}{l}\text { Area } \\
\text { (m2) }\end{array}$ & 305 & 480.91 & 549.16 & 226.7 & 40.25 & 20.85 \\
\hline $\begin{array}{l}\text { Volum } \\
\text { e (m3) }\end{array}$ & 823.5 & 1298.4 & 1482.7 & 680.1 & 120.75 & 62.55 \\
\hline Total & 45 & 56 & 88 & 21 & 5 & 3 \\
\hline $\begin{array}{l}\text { Investi } \\
\text { gated }\end{array}$ & $\begin{array}{c}14 \text { of } \\
20\end{array}$ & $\begin{array}{c}19 \mathrm{~s} \text { of } \\
33\end{array}$ & $\begin{array}{c}20 \text { of } \\
35\end{array}$ & 17 of 21 & 4 of 5 & 3 of 3 \\
\hline
\end{tabular}

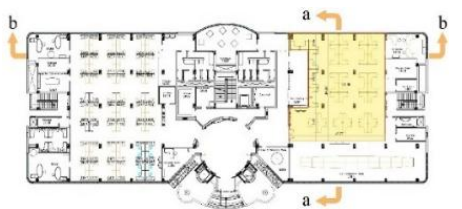

(a)

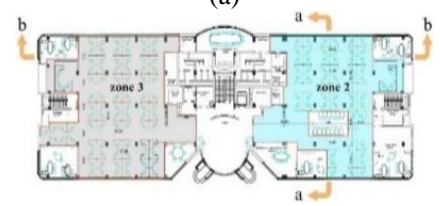

(c)

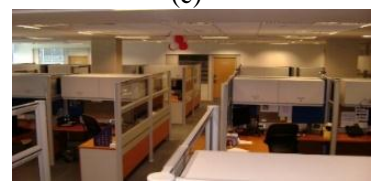

(e)

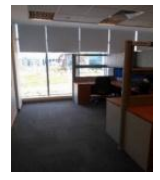

(b)

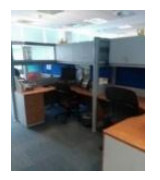

(d)

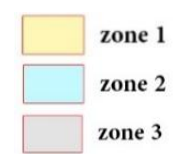

Figure 3. (a) B3 ground floor plan, (b) Z1-B3, (c) B3 1st floor plan, (d) Z2-B3 (e) Z3-B3 in March 2017

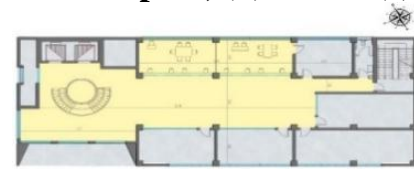

(a)

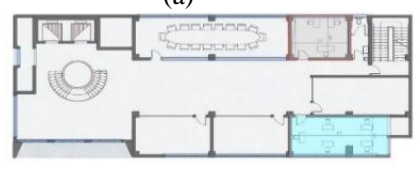

(c)

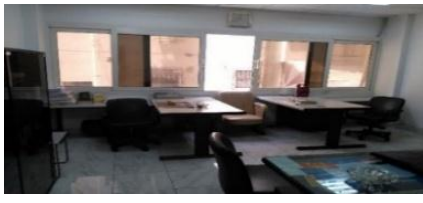

(e)

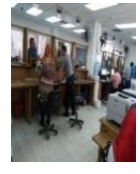

(b)

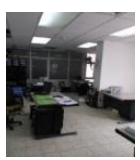

(d)

zone 1

zone 2

zone 3
Figure 4. (a) PCC 1st floor plan, (b) Z1-PCC, (c) PCC 1st floor plan, (d) Z2-PCC (e) Z3-PCC in March, May 2017

\subsection{Respondent characteristics}

The survey results that a large proportion of respondents had symptoms compatible with the SBS symptoms. Besides, a selection of bias can be occurred because of inequity in the respondent rates and then, possibly affected by the prevalence of SBS symptoms. A 
total of 53 respondents were handed out the questionnaires in B3. The respondents' rate responded to the questionnaires are Z1-B3, Z2-B3 and Z3-B3 were 8, 15 and 14, respectively. While A total of 23 respondents were handed out the questionnaires in PCC building. The respondents' rate responded to the questionnaires are $\mathrm{Z1}$ PCC, Z2-PCC and Z3-PCC were 17, 3 and 3, respectively. The socio demographic information was derived from the questionnaires by the respondents in there selected buildings as tabulated in Table 2. In B3 the proportions of male and female respondents were almost equivalent for zone 1 and zone 2 . The mean age of respondents was 3039 years in the tree zones. The mean number of hours per week respondents spent in the buildings was $40.30 \mathrm{~h}$. While in PCC the proportions of male and female respondents were not equivalent for the three zones. The mean age of respondents was 30-39 years in the tree zones. The mean number of hours per week respondents spent in the buildings was $30 \mathrm{~h}$.

Table 2: Characteristics of respondents

\begin{tabular}{|c|c|c|c|c|c|c|c|c|}
\hline \multirow{2}{*}{\multicolumn{3}{|c|}{ Building }} & \multicolumn{3}{|c|}{ B3 } & \multicolumn{3}{|c|}{ PCC } \\
\hline & & & $\begin{array}{l}\text { Z1- } \\
\text { B3 }\end{array}$ & $\begin{array}{l}\text { Z2- } \\
\text { B3 }\end{array}$ & $\begin{array}{l}\text { Z3- } \\
\text { B3 }\end{array}$ & $\begin{array}{c}\text { Z1- } \\
\text { PCC }\end{array}$ & $\begin{array}{l}\text { Z2- } \\
\text { PCC }\end{array}$ & $\begin{array}{l}\text { Z3- } \\
\text { PCC }\end{array}$ \\
\hline \multirow{3}{*}{$\mathbf{z}$} & \multicolumn{2}{|c|}{$T$} & 14 & 20 & 19 & 14 & 4 & 3 \\
\hline & \multicolumn{2}{|c|}{$\begin{array}{c}\text { Fema } \\
\text { le }\end{array}$} & 7 & 10 & 8 & 7 & 3 & $\mathbf{0}$ \\
\hline & \multicolumn{2}{|c|}{ Male } & 7 & 10 & 11 & 7 & 1 & 3 \\
\hline \multirow{2}{*}{ 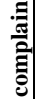 } & \multirow{2}{*}{ 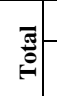 } & $\mathbf{z}$ & 8 & 15 & 14 & 8 & 4 & 3 \\
\hline & & $\therefore$ & 57 & 75 & 73.6 & 57.1 & 25 & 100 \\
\hline \multirow{4}{*}{ 苛 } & \multirow{4}{*}{ 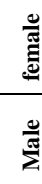 } & $\mathrm{z}$ & 5 & 10 & 8 & 5 & 3 & $\mathbf{0}$ \\
\hline & & $5^{\circ}$ & 62.5 & 66.6 & 57.1 & 62.5 & 75 & $\mathbf{0}$ \\
\hline & & $\mathbf{Z}$ & 3 & 5 & 6 & 3 & 1 & 3 \\
\hline & & $5^{\circ}$ & 37.5 & 33.3 & 42.9 & 37.5 & 25 & 100 \\
\hline \multirow{6}{*}{ 品 } & 2 & $\mathbf{z}$ & 1 & 2 & 3 & 2 & $\mathbf{0}$ & $\mathbf{0}$ \\
\hline & สิ่ & $0^{\circ}$ & 12.5 & 13.4 & 21.4 & 25 & $\mathbf{0}$ & $\mathbf{0}$ \\
\hline & \multirow{2}{*}{ 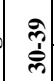 } & $\mathbf{z}$ & 5 & 10 & 6 & 4 & 4 & $\mathbf{0}$ \\
\hline & & $0^{\circ}$ & 62.5 & 66.6 & 42.8 & 50 & 100 & $\mathbf{0}$ \\
\hline & \multirow{2}{*}{$\begin{array}{l}\stackrel{q}{\alpha} \\
\hat{f}\end{array}$} & $\mathbf{z}$ & 2 & 3 & 5 & 2 & $\mathbf{0}$ & 3 \\
\hline & & $\therefore$ & 25 & 20 & 35.8 & 25 & $\mathbf{0}$ & 100 \\
\hline \multicolumn{3}{|c|}{ Smokers } & 1 & 6 & 3 & 2 & $\mathbf{0}$ & $\mathbf{0}$ \\
\hline \multicolumn{3}{|c|}{$\begin{array}{c}\text { Allergic } \\
\text { status }\end{array}$} & 3 & 2 & 3 & 6 & 0 & 0 \\
\hline \multicolumn{3}{|c|}{$\begin{array}{l}\text { Work } \\
\text { time (h) }\end{array}$} & \multicolumn{3}{|c|}{40.30} & \multicolumn{3}{|c|}{30} \\
\hline
\end{tabular}

\subsection{Occurrence of SBS:}

In B3 the problem of sick building syndrome was first recognized through occupants' complaints that provided information about the way occupants understand the problem. Therefore, the study began with discussions with occupants documenting their complaints to provide a basis for the problem. Each participant was asked to assess his office environmental quality. Some questions used open ended answers while others ended with specific answers to choose from. Table 3 shows the symptoms that experienced by the participant and complied with the questionnaire answers, and possible causes of the complaints according to the building evaluation. To find out if there were building syndrome problems, the frequency of complaints or symptoms of illness was defined. Standards determine the acceptable indoor air quality where there are no known complaints at harmful levels (with which $80 \%$ or more of occupants don't express dissatisfaction, also SBS in oracle building is considered a permanent as its causes are results of indoor air quality problems and pollutants high concentration. Table 3 showed the symptoms and their possible pollutants and parameters. The first target was to estimate the building symptom index (the average number of symptoms per occupant) and the frequency of the symptoms of illness at the three selected zones.

Unlike B3 building, the problem of sick building syndrome in PCC was first recognized through building performance, the study began with discussions with occupants, all of them complain of ventilation and thermal discomfort as the building was natural ventilated in winter and spring (duration from November to may) while it was mechanically ventilated in summer and autumn (duration from June to October). There were renovation currently occurs in ventilation system, and the rates used in simulation were the new rates known by checking the Quantities and specifications documents of the process. Occupants' complaints provide a basis for the problem and their answers on questionnaire and the building evaluation in Table 3 helped to identify the possible causes.

Table 3: Symptoms and their possible causes and parameters

\begin{tabular}{|c|c|c|c|}
\hline \multicolumn{4}{|c|}{ parameters } \\
\hline $\begin{array}{l}\text { sym } \\
\text { ptom }\end{array}$ & Possible Causes & B3 & PCC \\
\hline \multirow{6}{*}{ 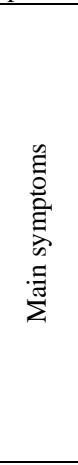 } & $\begin{array}{l}\text { environmental } \\
\text { parameters }\end{array}$ & $\begin{array}{c}\text { - Ventilation } \\
\text { problems; } \\
\text { insufficient } \\
\text { fresh air } \\
\text { - } \quad \text { Materials }\end{array}$ & $\begin{array}{l}\text { Ventilation problems; } \\
\text { insufficient fresh air, } \\
\text { inadequate ventilation }\end{array}$ \\
\hline & \multirow{5}{*}{ pollutant } & $\begin{array}{l}\text { Carbon dioxide } \\
(\mathrm{CO} 2)\end{array}$ & Carbon dioxide (CO2) \\
\hline & & $\begin{array}{l}\text { Carbon } \\
\text { monoxide }\end{array}$ & $\begin{array}{l}\text { Carbon monoxide } \\
\text { (Marino, Nucara et al.) }\end{array}$ \\
\hline & & VOCs & VOCs \\
\hline & & \multirow{2}{*}{$\begin{array}{l}\text { Benzene, } \\
\text { toluene }\end{array}$} & $\begin{array}{ll}\begin{array}{l}\text { Nitrogen } \\
(\mathrm{NO} 2)\end{array} & \text { dioxide } \\
\end{array}$ \\
\hline & & & $\begin{array}{l}\text { Environmental tobacco } \\
\text { smoke (ETS) }\end{array}$ \\
\hline \multirow{4}{*}{ 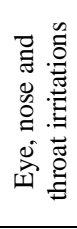 } & $\begin{array}{l}\text { environmental } \\
\text { parameters }\end{array}$ & $\begin{array}{c}-\quad \text { Artificial } \\
\text { lights, Daylight. } \\
-\quad \text { Materials } \\
\end{array}$ & $\begin{array}{l}\text { Artificial lights, } \\
\text { Daylight }\end{array}$ \\
\hline & \multirow{3}{*}{ pollutant } & Nitrogen oxides & Nitrogen oxides \\
\hline & & $\begin{array}{ll}\begin{array}{l}\text { Ozone, } \\
\text { dioxide }\end{array} & \text { sulfur } \\
\end{array}$ & Ozone, sulfur dioxide \\
\hline & & Formaldehyde & Formaldehyde \\
\hline \multirow[t]{2}{*}{ 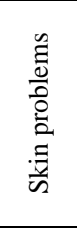 } & $\begin{array}{l}\text { environmental } \\
\text { parameters }\end{array}$ & $\begin{array}{l}\text { - Low relative } \\
\text { humidity, warm } \\
\text { temperatures, } \\
\text { air movement. } \\
\text { - Materials }\end{array}$ & $\begin{array}{l}\text { high relative humidity, } \\
\text { warm temperatures }\end{array}$ \\
\hline & pollutant & fibers & $\begin{array}{l}\text { Fibers, fungal growth, } \\
\text { dust, bacteria }\end{array}$ \\
\hline
\end{tabular}

The survey revealed that main symptoms (e.g. Headache, Lethargy, Fatigue, Poor concentration) were the most widely-reported symptom in the six zones that is perceived to be building-related. Apart from nose discomfort, Table 4 showed the percentages of all reported symptoms at the six office hall of the two buildings, including eye discomfort throat discomfort and 
breathing problems Skin discomfort (e.g. allergy, dry skin).

Table 4: Occurrence of SBS symptoms in the two buildings

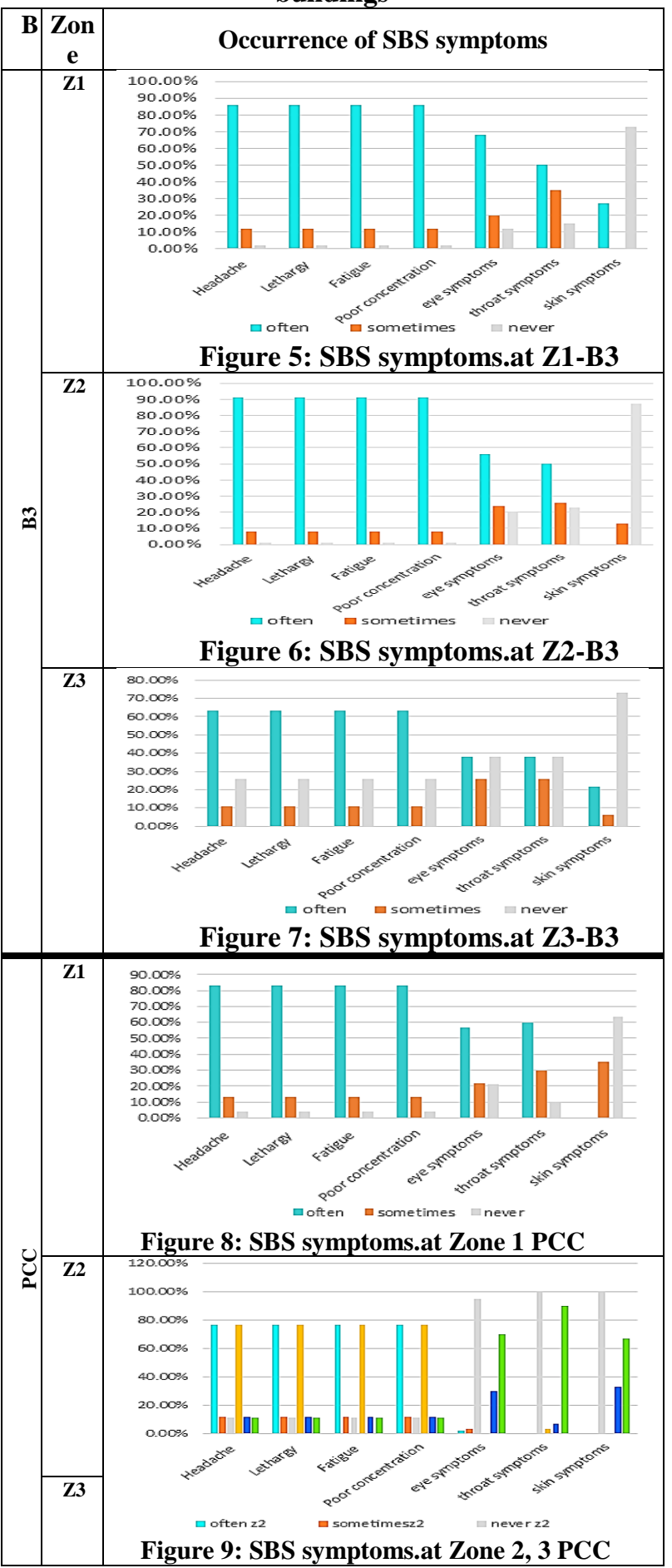

4.5. Correlation among different parameters and mean SBS symptoms/person:

1. Age vs. SBS symptoms:

Figure 10 describes the distribution of SBS symptoms/person for respective age groups in six zones of the two buildings. It was found that the Occupants in the age group of 30-39 were more susceptible to SBS symptoms as compared to the occupants in the age group of 50-59. It did not necessarily reflect that occupants in the age group of 50-59 were not having any health complaints. They might be having chronic health problems, which remained unaffected even after leaving the building.

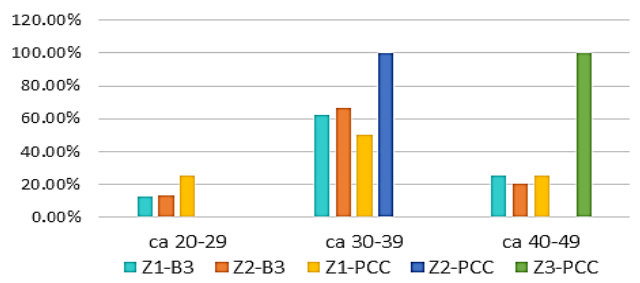

Figure 10: Association between Worker's age and SBS symptoms per person.at the two buildings

\section{Workers gender vs. SBS symptoms:}

Out of the total occupancy level in zone 1, there were $50 \%$ females and $50 \%$ males. Females were showing $71.4 \%$ more SBS symptoms as compared to males who reported $24.8 \%$ Figure 11 shows that female gender was more sensitive to SBS symptoms than male, thus needing a lesser dose of pollutants to response to the sick building symptoms.

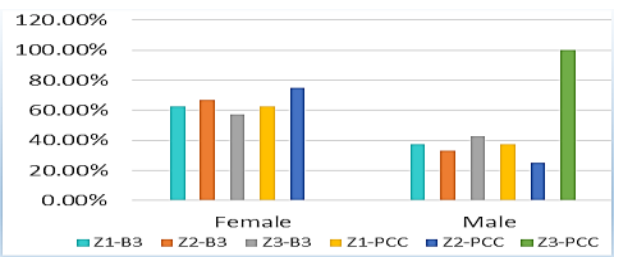

Figure 11: Association between Worker's gender and SBS symptoms per person.at the two buildings

\section{Percentage dissatisfied of the IEQ factors:}

Figure 12 illustrates the mean satisfaction ratings for overall building zones and the 12 IEQ factors by respondent employees. In general, thermal/air ('temperature' and 'air quality'), acoustical condition ('noise' and 'sound privacy'), and lighting ('visual comfort' and 'amount of light') were evaluated poorly compared to the rest of IEQ factors.

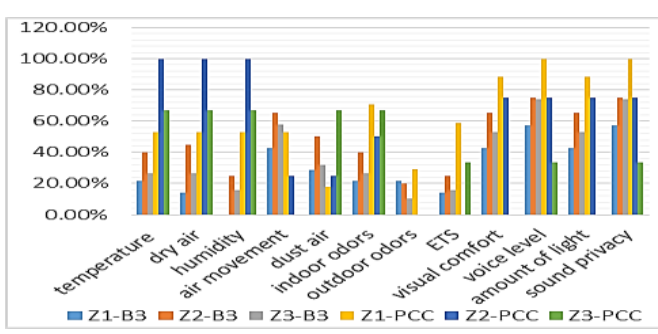

Figure 12: dissatisfied of the IEQ factors among six zones of the two buildings

4. Job stress vs. SBS symptoms:

in B3 The relation between SBS symptoms/person and job stress rating on Z2-B3 was having maximum SBS symptoms as the nature of the job was quite tough and demanding. The occupants on this zone were getting stress allowance as well. in PCC The relation between SBS symptoms/person and job stress rating on zone 1 was having maximum SBS symptoms as the nature of the job was quite tough and dealing with the public. The 
occupants on this zone were getting stress allowance as well. Figure 13 shows the percentage distribution of job stress in each zone of the building.

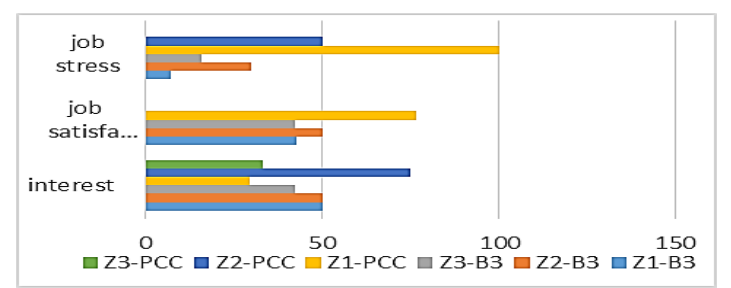

Figure 13: Job stress vs. SBS symptoms among six zones of the two buildings

\subsection{Contaminants concentration as an indicator of IAQ problems and occurrence of SBS:}

Contaminant simulations were performed for four contaminants: total volatile organic compound (TVOCs), Benzene, Toluene, and Formaldehyde. The VOC is not intended to represent any specific compound or compounds, but rather to represent a generic indoor source associated with building materials.

Table 5 show B3 Building's products and pollutants acrylic painting of walls, gypsum board ceiling and floors, polypropylene carpets, and furniture from particle boards and MDF. Benzene and Toluene emitted compounds from acrylic painting, varnish covering of furniture, and adhesives. Formaldehyde from particle board and MDF. Also shows PCC building's Contaminant simulations were performed for four contaminants: total volatile organic compound (TVOCs), Benzene, Toluene, and Formaldehyde for zone 1, and total volatile organic compound (TVOCs), Benzene, Toluene for zones 2, 3. indoor source associated with building materials acrylic painting of walls, gypsum board ceiling, MDF partition, and Benzene and Toluene emitted compounds from acrylic painting, varnish covering of MDF partition. Formaldehyde from MDF.

The simulation occurred in $23^{\circ} \mathrm{C}$, R.H $50 \%$, air velocity $0.05 \mathrm{~m} / \mathrm{s}$, intensity $1 \%$, and ventilation air flow rates from $5 \mathrm{~L} / \mathrm{s}$ to $15 \mathrm{~L} / \mathrm{s}$ according to the technical investigation and the simulation tool's settings. Simulation duration was one month (720h).

Table 5: Building materials and pollutants

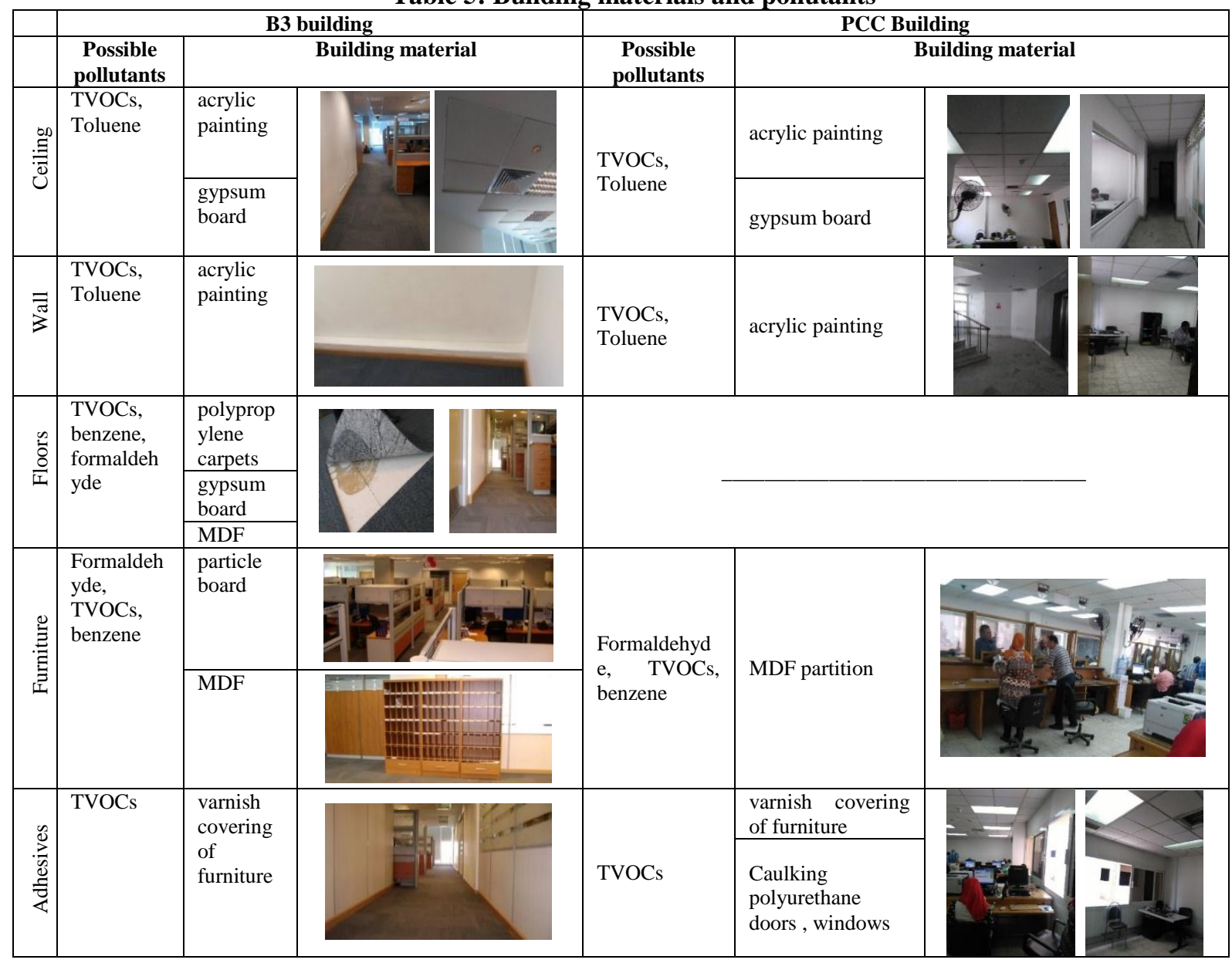

1. Mechanical Ventilation rates:

Figures below show ventilation rates in six selected zones of the two buildings according to the technical investigation 


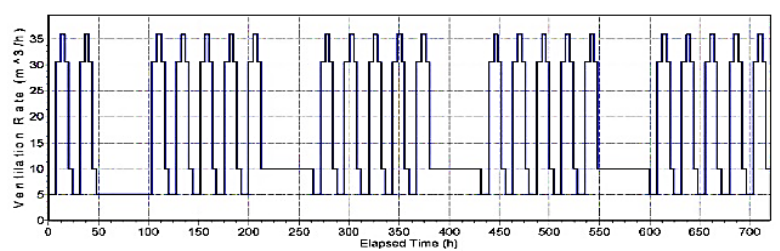

Figure 14: Hourly average of Ventilation rates in Z1-B3

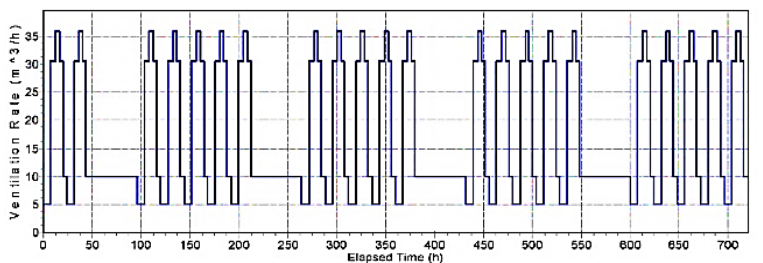

Figure 15: Hourly average of Ventilation rates in Z2-B3

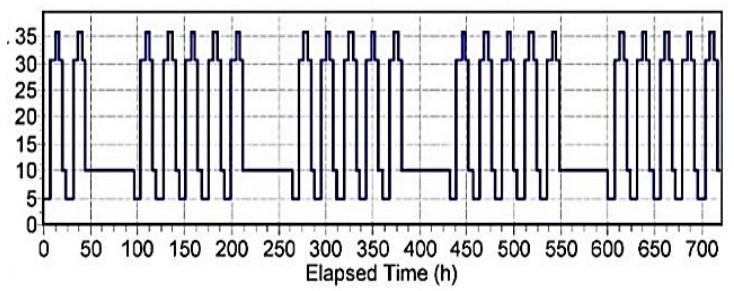

Figure 16: Hourly average of Ventilation rates in Z3-B3

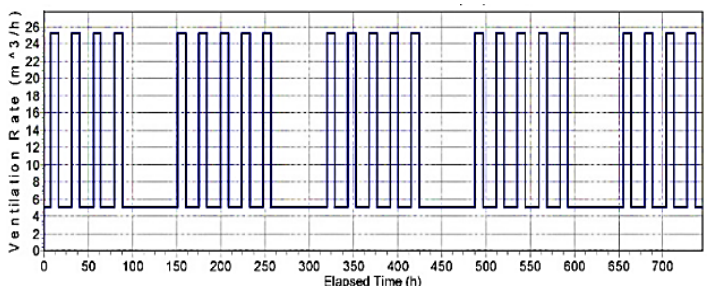

Figure 17: Hourly average of mechanical Ventilation rates in $\mathrm{Z1}$ PCC

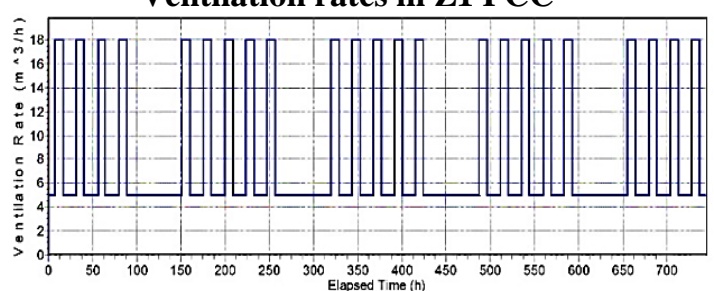

Figure 18: Hourly average of mechanical Ventilation rates in $\mathrm{Z2}$ PCC

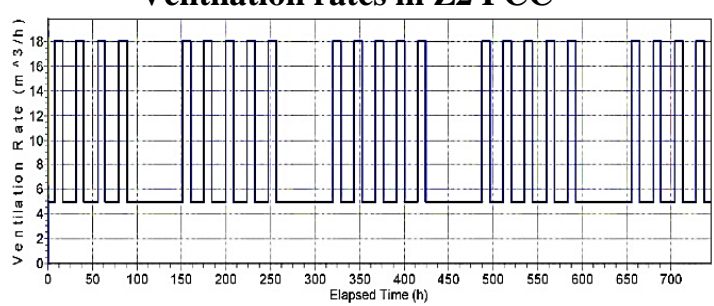

Figure 19: Hourly average of mechanical Ventilation rates in $\mathrm{Z3}$ PCC

2. Natural ventilation rates in PCC:

With the unpredictable nature of wind, it is commonly recommended to base the size and location of openings on a scenario where the air flow is purely driven by buoyancy effects. With this approach, the wind will work to assist the natural ventilation, but is not required to achieve the design minimum air flows.
- $\quad$ Winter Operating Mode with Displacement Ventilation (IP):

The calculation of natural ventilation rate for March 2017According to weather forecast, In Port Said, the month of March is characterized by gradually rising daily high temperatures, with daily highs increasing by $3^{\circ} \mathrm{F}$, from $66^{\circ} \mathrm{F}$ to $69^{\circ} \mathrm{F}$ over the course of the month, and rarely exceeding $77^{\circ} \mathrm{F}$ or dropping below $60^{\circ} \mathrm{F}$.

Daily low temperatures increase by $3^{\circ} \mathrm{F}$, from $55^{\circ} \mathrm{F}$ to $59^{\circ} \mathrm{F}$, rarely falling below $51^{\circ} \mathrm{F}$ or exceeding $62^{\circ} \mathrm{F}$.

- Wind

Figure 20 discusses the wide-area hourly average wind vector (speed and direction) at 10 meters above the ground. The wind experienced at any given location is highly dependent on local topography and other factors, and instantaneous wind speed and direction vary more widely than hourly averages.

The average hourly wind speed in Port Said is essentially constant during March, remaining within0.1 miles per hour of 5.8 miles per hour throughout.

For reference, on February 7, the windiest day of the year, the daily average wind speed is6.0 miles per hour, while on August 16, the calmest day of the year, the daily average wind speed is 4.9 miles per hour.

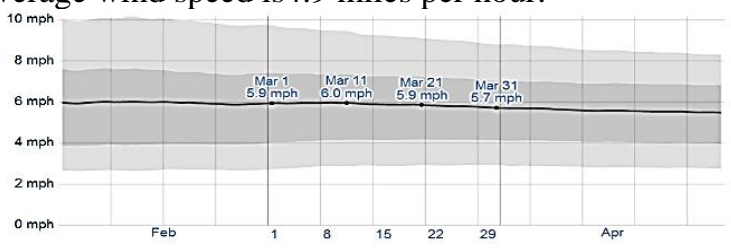

Figure 20: Average wind speed in March

- $\quad$ Calculating the natural ventilation rate:

The calculation was for zone2 and zone3, From ASHRAE Standard 62.1, the ventilation rate for office building can be determined from:

Airflow, $\mathrm{Q}$ is given by the equation

$$
\mathbf{Q}=\mathbf{E} \times \mathbf{A} \times \mathbf{V}
$$

Where

$Q=$ air flow in $\mathrm{m}^{3} / \mathrm{s}$

$A=$ free area of inlet openings in $m^{2}$

$V=$ wind velocity in $\mathrm{m} / \mathrm{s}$

$E=$ effectiveness of openings (0.025)

A. Calculation for Z2-PCC:

By the previous equation air flow rates were calculated in Z2-PCC as shown in Figure 21 bellow Z2-PCC is a single sided ventilated zone with a window $1.5 \mathrm{~m}$ width and $1.8 \mathrm{~m}$ height.

According to weather forecast of Port Said in March 2017, wind velocity average was $5.7 \mathrm{mph}$ to $6 \mathrm{mph}$, in all days minimum wind velocity was in duration from $12 \mathrm{am}$ to $2 \mathrm{pm}$, the maximum wind speed in duration from $4 \mathrm{pm}$ to $8 \mathrm{pm}$.

So,

Normal ventilation rates in Z2-PCC was

$$
\begin{aligned}
\mathrm{Q}=0.025 \times 2.7 \times 2.63=0.1775 \mathrm{~m}^{3} / \mathrm{s} \\
=639 \mathrm{~m}^{3} / \mathrm{h}
\end{aligned}
$$

Minimum ventilation rates in $\mathrm{Z} 2-\mathrm{PCC}$ was

$$
Q=0.025 \times 2.7 \times 2.54=0.1717 \mathrm{~m}^{3} / \mathrm{s}
$$




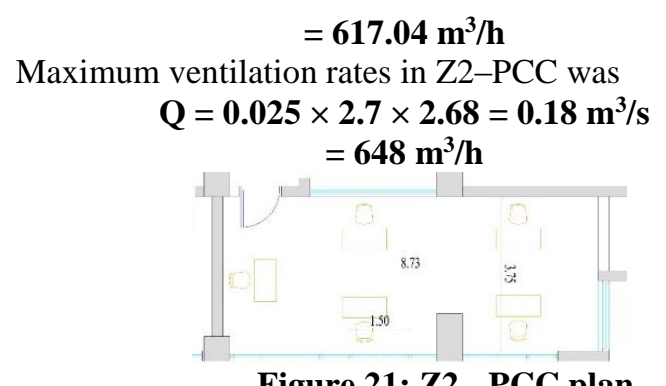

Figure 21: Z2 - PCC plan

\section{B. Calculation for Z3-PCC:}

The same in Z3-PCC that was single sided ventilated zone with a window $3.00 \mathrm{~m}$ width and $1.8 \mathrm{~m}$ height, and ventilation rates was calculated with the same formula with the same conditions.

Normal ventilation rates in Z2-PCC was

$$
\begin{gathered}
Q=0.025 \times 5.4 \times 2.63=0.355 \mathrm{~m}^{3} / \mathrm{s} \\
=1278 \mathrm{~m}^{3} / \mathrm{h}
\end{gathered}
$$

Minimum ventilation rates in $\mathrm{Z} 2-\mathrm{PCC}$ was

$$
\begin{aligned}
Q=0.025 & \times 5.4 \times 2.54=0.342 \mathrm{~m}^{3} / \mathrm{s} \\
& =1231.2 \mathrm{~m}^{3} / \mathrm{h}
\end{aligned}
$$

Maximum ventilation rates in $\mathrm{Z} 2-\mathrm{PCC}$ was

$$
\begin{gathered}
Q=0.025 \times 5.4 \times 2.68=0.361 \mathrm{~m}^{3} / \mathrm{s} \\
=1302.48 \mathrm{~m}^{3} / \mathrm{h}
\end{gathered}
$$

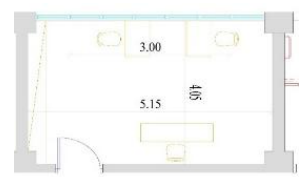

Figure 22: Z3 - PCC plan

According to LEED requirements for naturally ventilated spaces demonstrate a distribution and laminar flow pattern that involves not less than $90 \%$ of the room or zone area in the direction of air flow

for at least $95 \%$ of hours of occupancy. The requirement is not achieved in PCC.

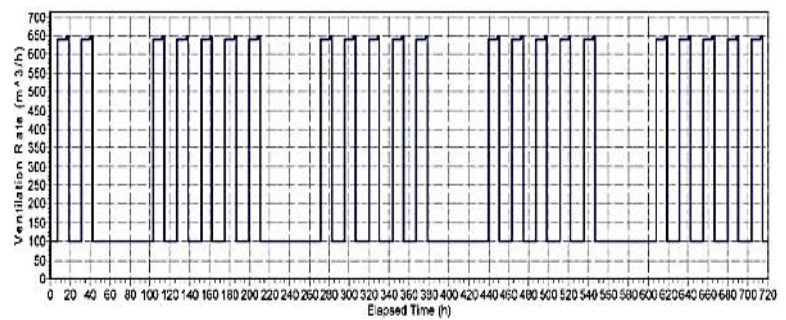

a. Hourly average of natural Ventilation rates in $\mathrm{Z2} \mathbf{P C C}$

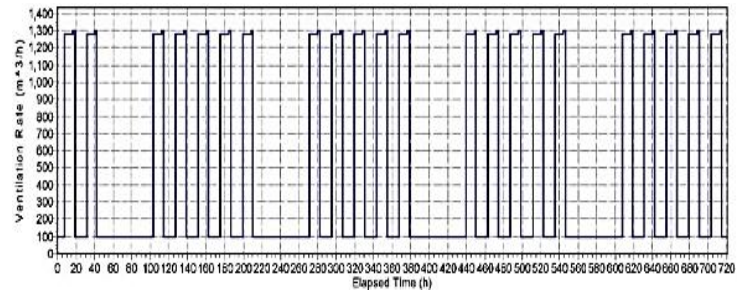

b. Hourly average of natural Ventilation rates in $\mathrm{Z3}$ PCC

Figure 23: natural Ventilation rates in the two selected zones of Port Said Chamber of commerce

\subsection{Simulation results:}

1. Contaminants concentration in B3:

The results of the contaminant simulations are summarized in Table 6 which lists the concentration of monthly average and monthly peak concentration for each contaminant. Thus, the values in the Table are not overall building minimum and maximum concentrations but only reflect the three selected zones. Figure 24 show the frequency graph of VOCs concentration for the three selected zones, Figure 25 show the frequency graph of formaldehyde concentration for the three selected zones, Figure 26 shows the frequency graph of benzene concentration for the three selected zones, and Figure 27 shows the frequency graph of Toluene concentration for the three selected zones.

According to the following graph figures, Z1-B3 and Z2-B3 were in comfort range after half an hour, but Z3B3 was in comfort range until an hour. Also Z1-B3 and $\mathrm{Z} 2-\mathrm{B} 3$ were in multi-factor range in the duration from half an hour to 5 hours, but Z3-B3 was in multi-factor range in the duration from an hour to 5 hours. at Z1-B3 the concentration of TVOCs was various in acceptable and toxic ranges, it was in discomfort range that considered the acceptable concentration according to EPA and WHO, in the duration from 5 hours to 70 hours, then the concentration increase to the toxic range in the duration from 70 hours to 135 hours, after that the concentration decrease to the acceptable range in the duration from 135 hours to 145 hours, then increase to the toxic range in the duration from 145 hours to 155 hours, after that it decreases to acceptable range in the duration from 155 hours to 247 hours, and increase to toxic range in the duration from 247 hours to 277 hours, finally it decrease to acceptable range in the duration from 277 hours to 720 hours. Contrariwise, at Z2-B3 the concentration of TVOC was in the toxic range in most duration among the month, from 53 hours to 690 hours and from 695 hours to 710 hours. The same in Z3-B3 that was in toxic range in the duration from 58 hours to 714 hours. The acceptable concentration ranges of TVOC in Z2-B3 were from 5 hours to 53 hours, from 690 hours to 695 hours, and from 710 hours to 720 hours. In Z3-B3 the acceptable concentration ranges of TVOC were from 5 hours to 58 hours and from 714 hours to 719 hours. Formaldehyde concentration in the three zones in the toxic range. Benzene concentration in all zones was in safe range. All zones have a safe toxic concentration of Toluene toxic range after 8 hours, all zones were in the safe range until 8 hours then concentration was variable in the toxic range.

\section{Contaminants concentration in PCC for} mechanical ventilation:

The three zones rated high concentration of TVOCs, Figure 28 show the frequency graph of VOCs concentration for the three selected zones, Figure 29 show the frequency graph of formaldehyde concentration for the three selected zones, Figure 30 show the frequency graph of Benzene concentration for the three selected zones, finally Figure 31 show the frequency graph of Toluene concentration for the three selected zones. 
According to the following graph figures, all zones have a high toxic concentration of TVOCs, Z1-PCC scored the highest concentration then Z2-PCC, and Z3-PCC was the lowest. The concentration of TVOC in Z1-PCC was in multi-factor range in the duration from 0 to half an hour, then the concentration increase to the acceptable range in the duration from half an hour to 2.5 hours, finally the concentration was varied in the toxic range in the duration from 2.5 hours to 720 hours. In Z2-PCC the concentration was in multi-factor range in the duration from 0 to half an hour, then the concentration increase to the acceptable range in the duration from half an hour to 3 hours, finally the concentration was varied in the toxic range in the duration from 3 hours to 720 hours. In Z3-PCC the concentration was in multi-factor range in the duration from 0 to half an hour, then the concentration increase to the acceptable range in the duration from half an hour to 5 hours, finally the concentration was varied in the toxic range in the duration from 5 hours to 720 hours.
Although formaldehyde found only in Z1-PCC, the concentration was safe until 4 hours and gradually increases to reach the toxic range and the maximum concentration in 655 hours, 485 hours, and 320 hours. Benzene concentration in all zones was in safe range, while the concentration of Toluene was in safe range both in Z2-PCC and Z3-PCC, but in Z1-PCC was in safe range just until 24 hours then it was in toxic range.

\section{Contaminants concentration in PCC for natural ventilation:}

With natural ventilation the two zones were in acceptable concentration range of TVOCs, Figure 32 show the frequency graph of VOCs concentration for the two zones, there were no formaldehyde in these zones, Figure 33 show the frequency graph of Benzene concentration for the two zones and show that the concentration in the safe range, finally Figure 34 show the frequency graph of Toluene concentration for the two zones and show that the concentration in the safe range.

Table 6: contaminants concentration in the 6 selected zones of the two buildings

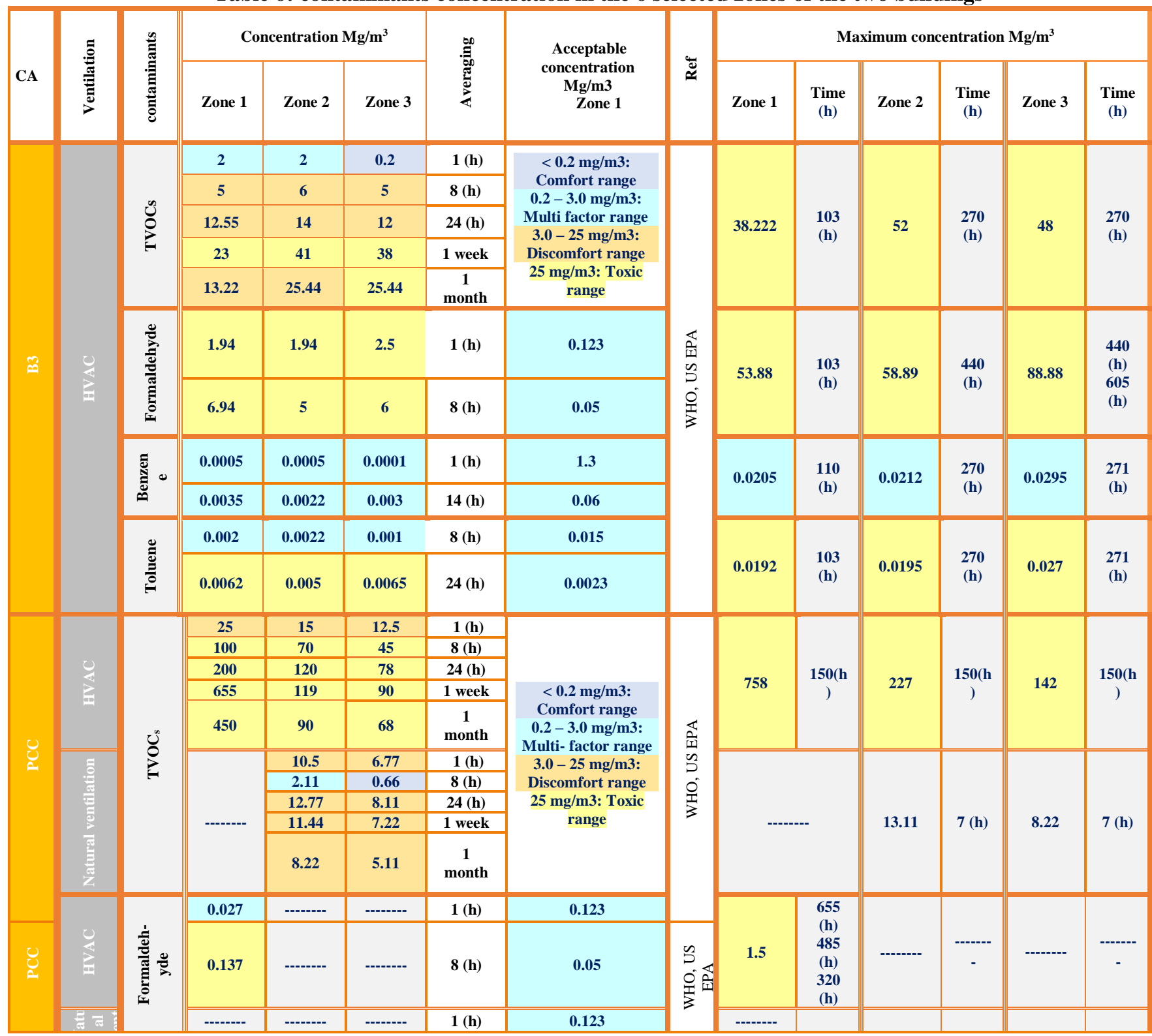




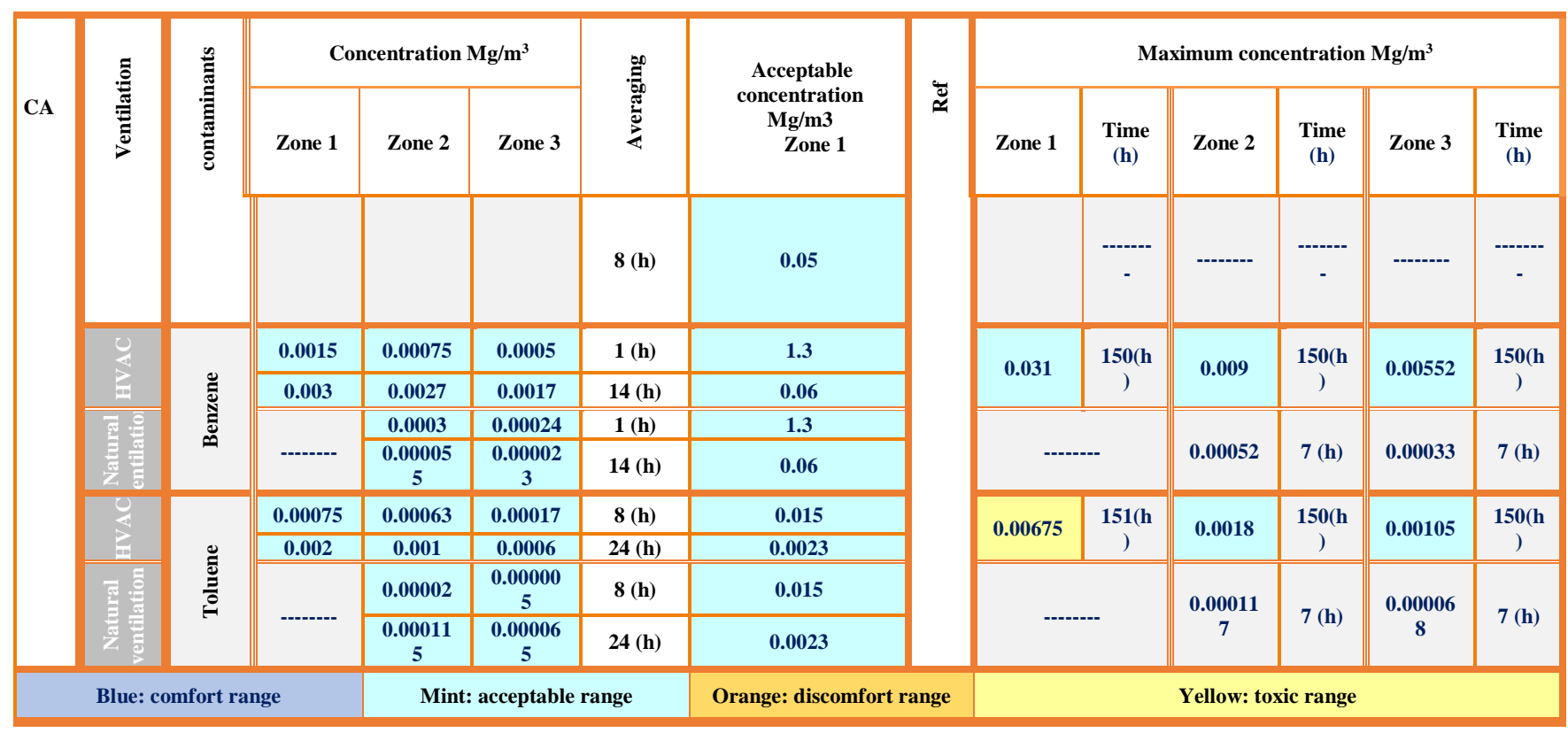

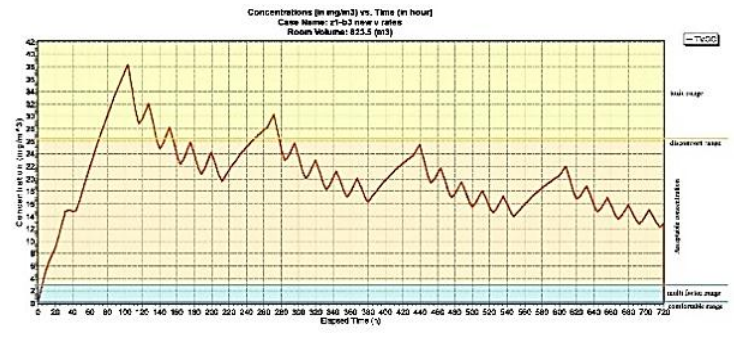

a. TVOCs concentration in Z1-B3

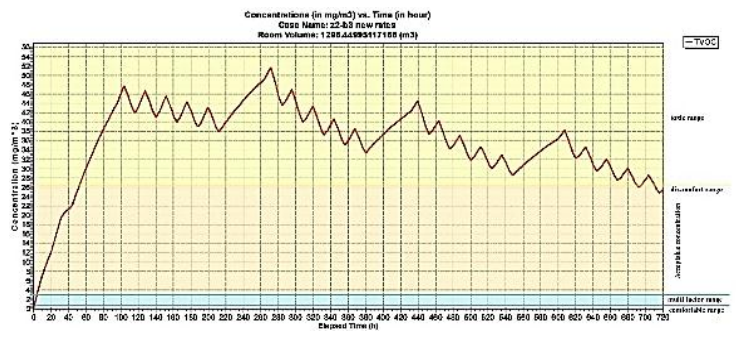

b. TVOCs concentration in $\mathbf{Z 2 - B 3}$

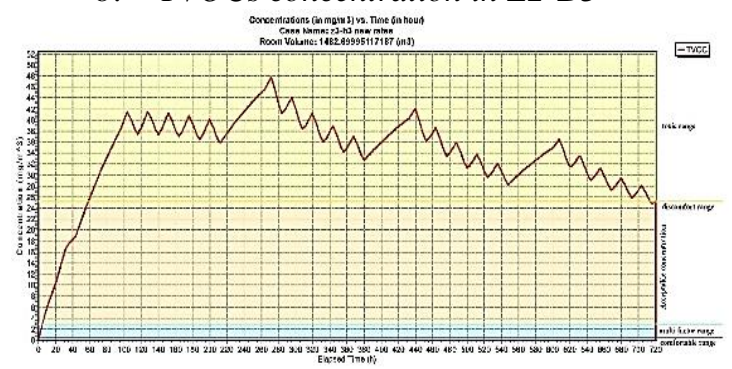

c. TVOCs concentration in Z3-B3

Figure 24: Time variation of VOC concentration for three selected zones of Oracle building

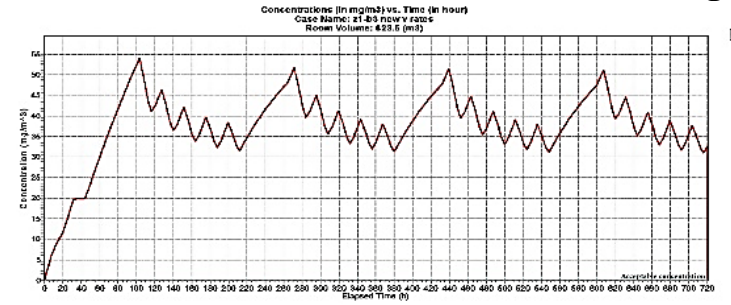

a. Formaldehyde concentration in Z1-B3

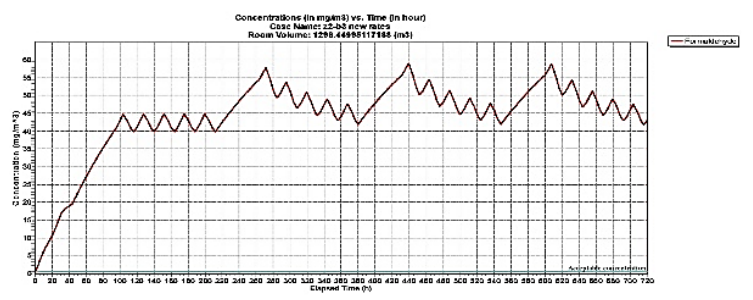

b. Formaldehyde concentration in $\mathbf{Z 2 - B 3}$

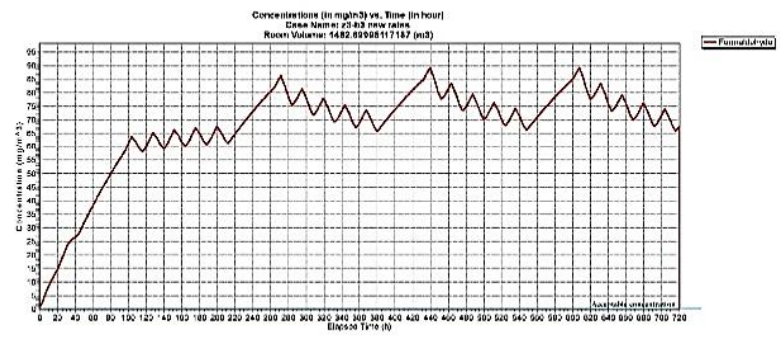

c. Formaldehyde concentration in Z3-B3

Figure 25: Time variation of formaldehyde concentration for three selected zones of Oracle building

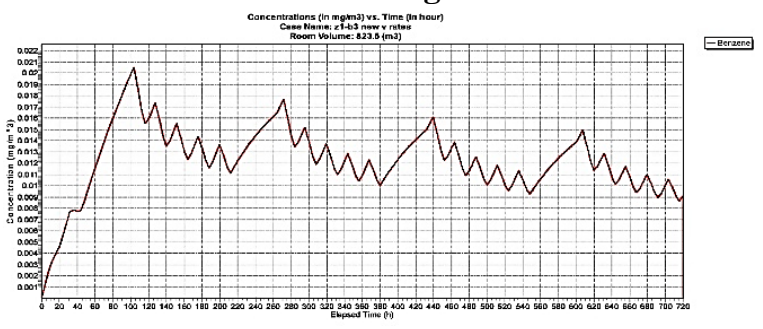

a. Benzene concentration in Z1-B3

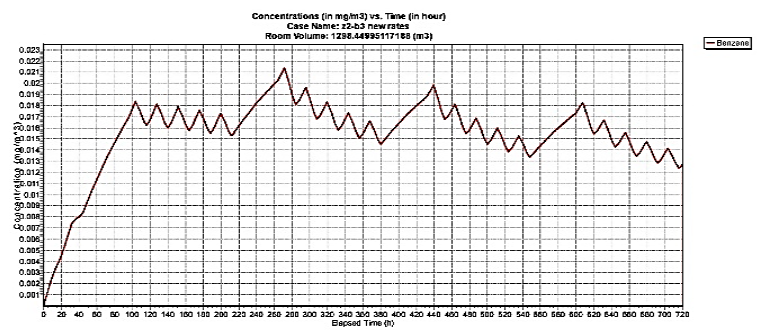

b. Benzene concentration in Z2-B3 


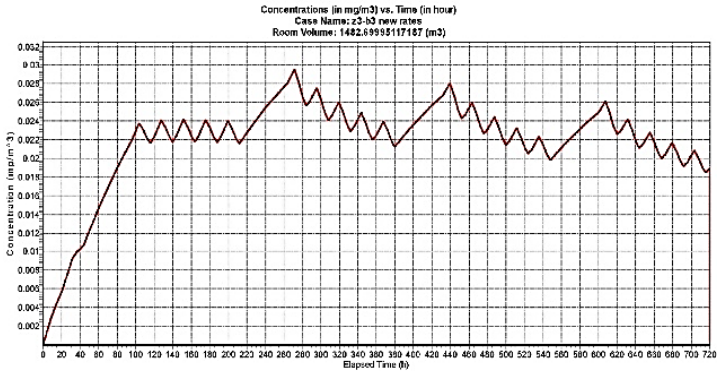

c. Benzene concentration in Z3-B3

Figure 26: Time variation of Benzene concentration for three selected zones of Oracle building

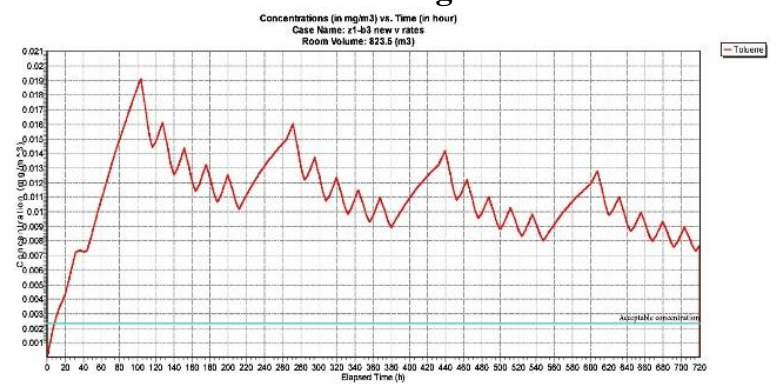

a. $\quad$ toluene concentration in Z1-B3

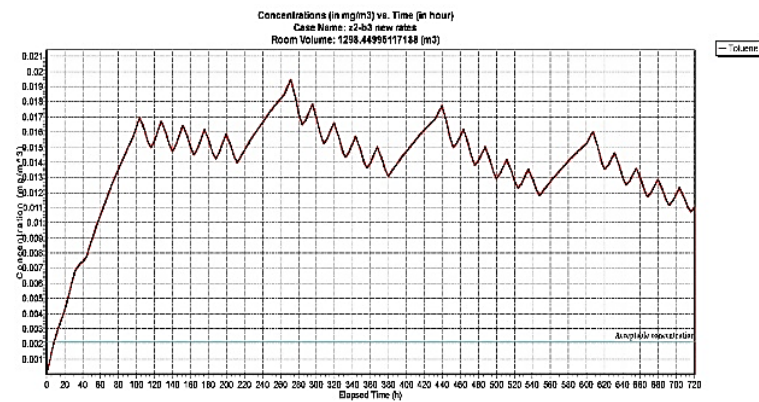

b. toluene concentration in $\mathbf{Z 2 - B 3}$

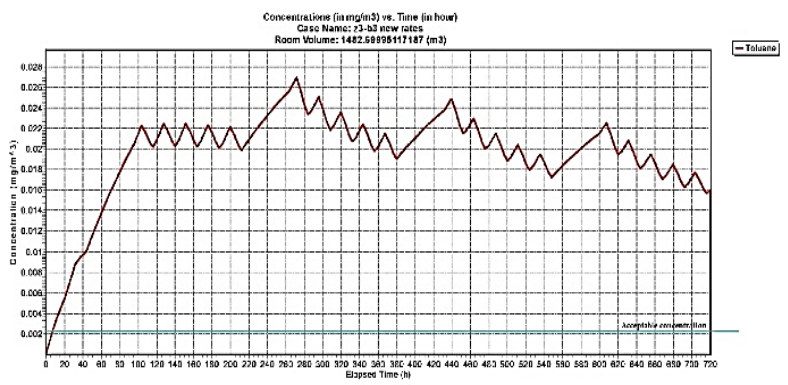

c. toluene concentration in Z3-B3

Figure 27: Time variation of Toluene concentration for three selected zones of Oracle building

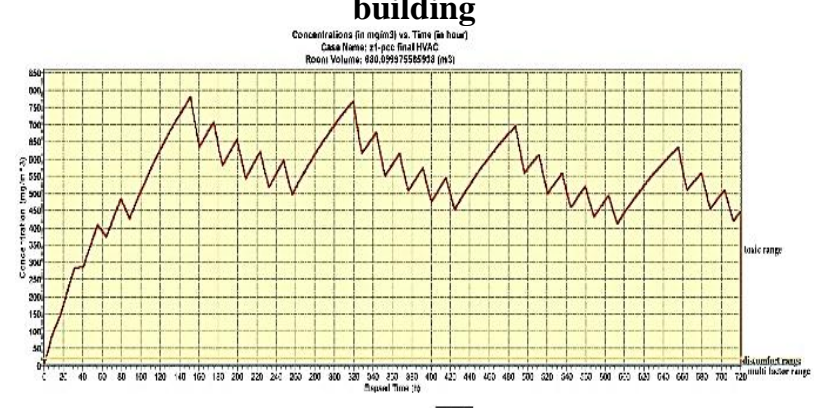
$\overline{-T \times S C}$

a. TVOCs concentration in Z1-PCC

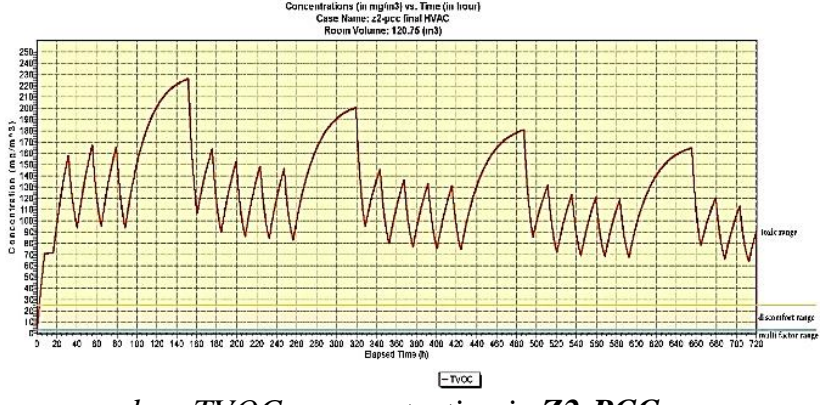

b. TVOCs concentration in Z2-PCC

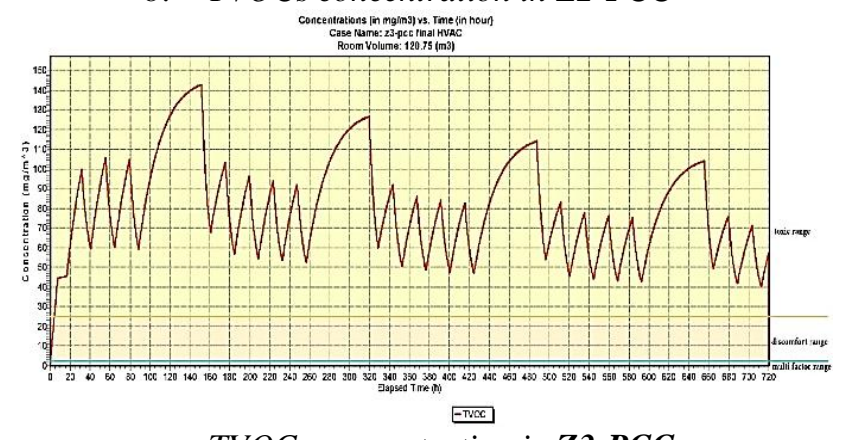

c. TVOCs concentration in Z3-PCC

Figure 28: Time variation of VOC concentration for three selected zones of Port Said Chamber of Commerce with HVAC

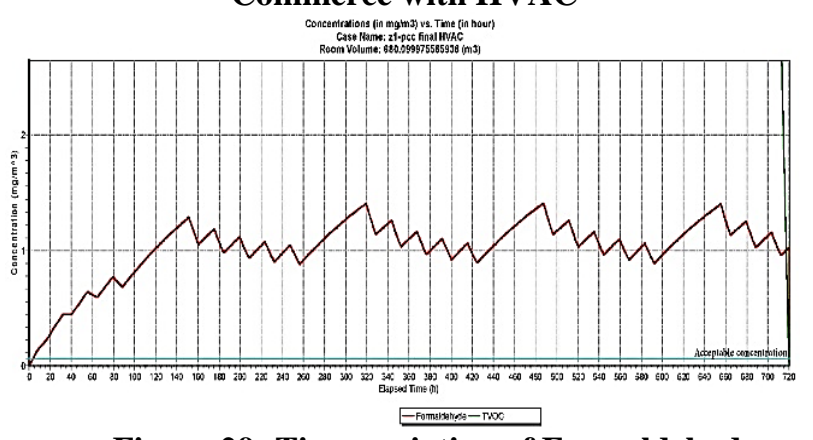

Figure 29: Time variation of Formaldehyde concentration for Z1PCC with HVAC

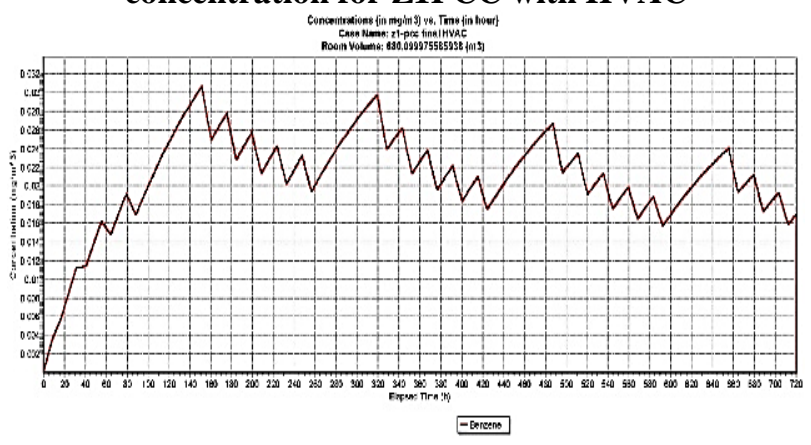

a. Benzene concentration in Z1-PCC

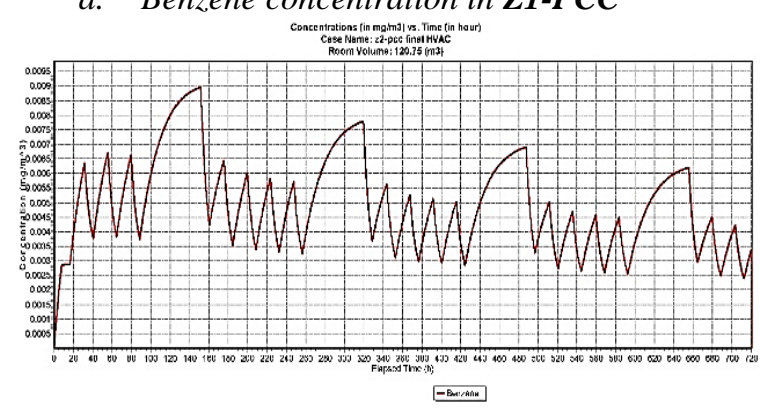

b. Benzene concentration in Z2-PCC 


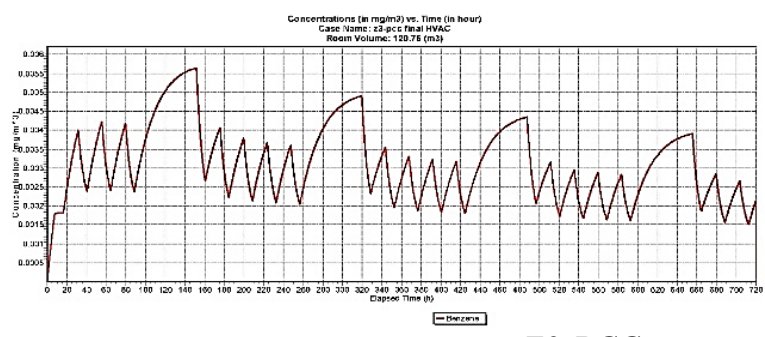

c. Benzene concentration in Z3-PCC

Figure 30: Time variation of Benzene concentration for Z1PCC with HVAC

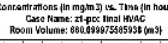

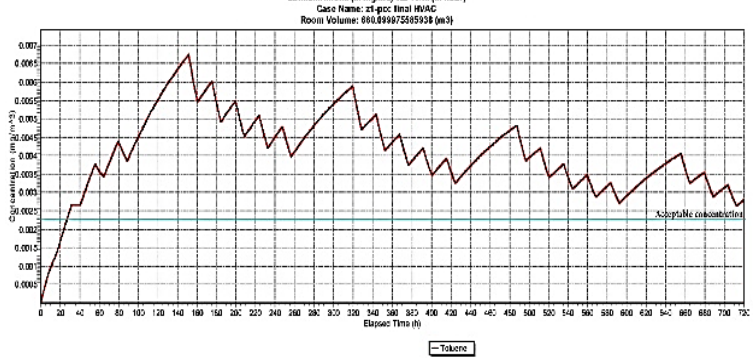

a. Toluene concentration in Z1-PCC

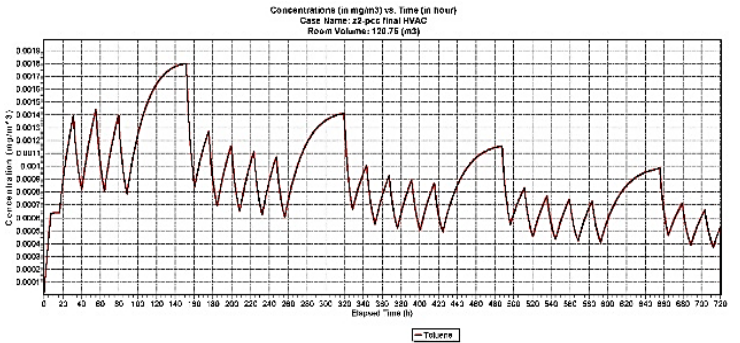

b. Toluene concentration in Z2-PCC

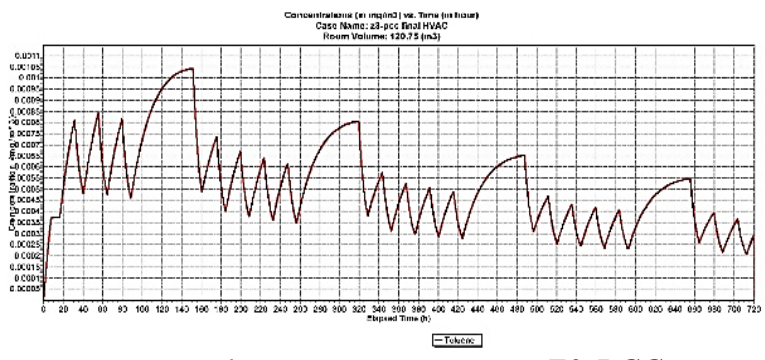

c. Toluene concentration in Z3-PCC

Figure 31: Time variation of Toluene concentration for Z1PCC with $\mathrm{H}$ VAC

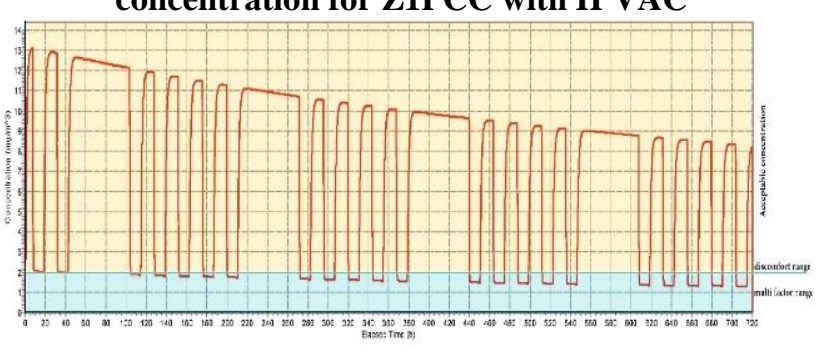

a. TVOCs concentration in Z2-PCC

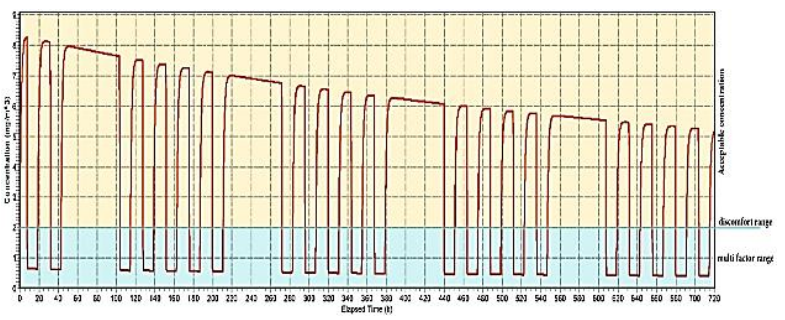

b. TVOCs concentration in Z3-PCC
Figure 32: Time variation of VOC concentration for two selected zones of Port Said Chamber of Commerce with natural ventilation

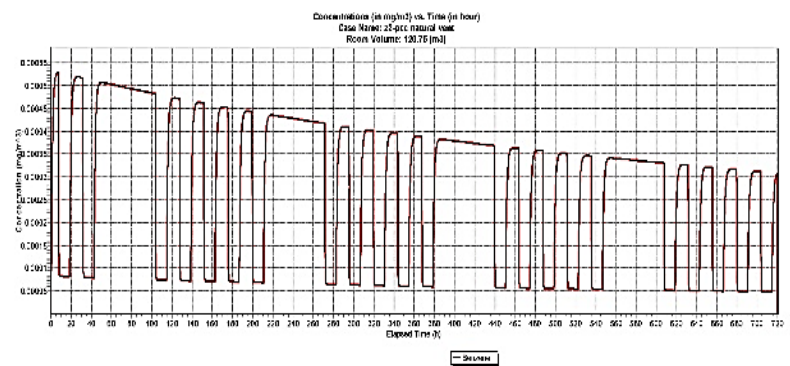

a. Benzene concentration in Z2-PCC

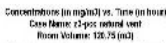

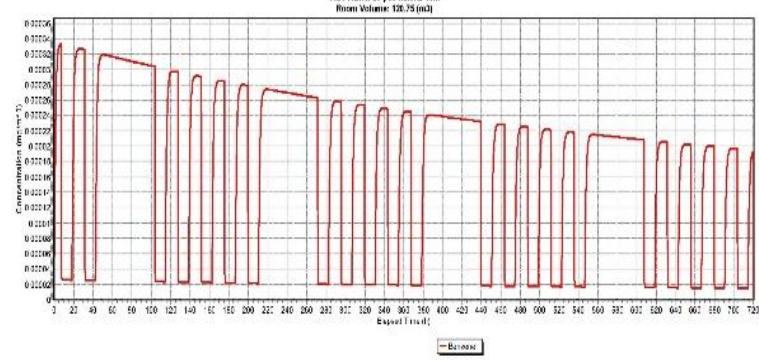

b. Benzene concentration in Z2-PCC

Figure 33: Time variation of Benzene concentration for two selected zones of Port Said Chamber of Commerce with natural ventilation

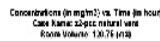

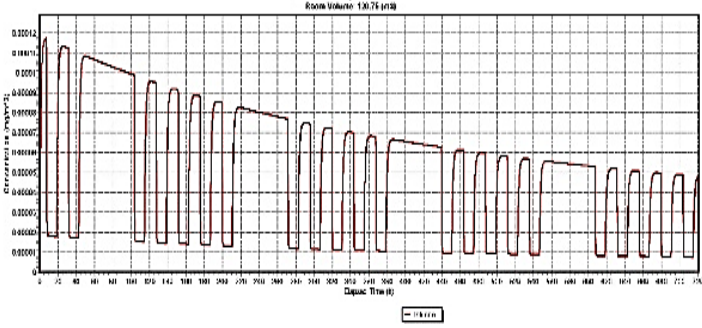

c. Toluene concentration in Z2-PCC

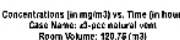

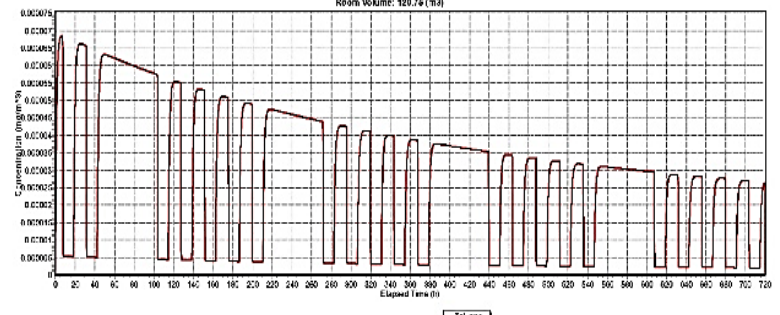

ETSed

d. Toluene concentration in Z3-PCC

Figure 34: Time variation of Toluene concentration for two selected zones of Port Said Chamber of Commerce with natural ventilation

\section{Discussion:}

The results can be divided into two stages. The first stage is exploring SBS symptoms in the two buildings. The second stage is identifying the possible causes related to indoor environmental quality of the buildings.

\subsection{First stage (exploring SBS):}

A comparative analysis made in six selected zones of buildings (Oracle, Chamber of commerce). The situation in Chamber of commerce considered the worst case, since about $100 \%$ of the participated occupants suffer from two 
or more symptoms. This exceeds the comfortable level in all health symptoms.

\subsection{Second stage (identifying the possible causes of SBS):}

\subsubsection{Ventilation:}

\section{A.Mechanical ventilation:}

In PCC building Symptoms were high at the first hours of the work days because ventilation problems caused by windows were closed or because of cleaning and maintenance activities or pollutants within the workspaces, also there was strong correlation between ventilation rates and very high concentration of contaminants, that cause high percentage of complaints, HVAC system works with lower rates than required in ASHARE standard and Egyptian code of ventilation.

Indoor air quality problems appeared as a result of low rates, also participated occupants were dissatisfied with thermal conditions in their workspaces. Contrariwise, Oracle building is an envelope but HVAC system works according to rates required in ASHARE standard and Egyptian code of ventilation, that makes results of contaminants concentration in rates lower than Chamber of Commerce building. As shown in figures below.

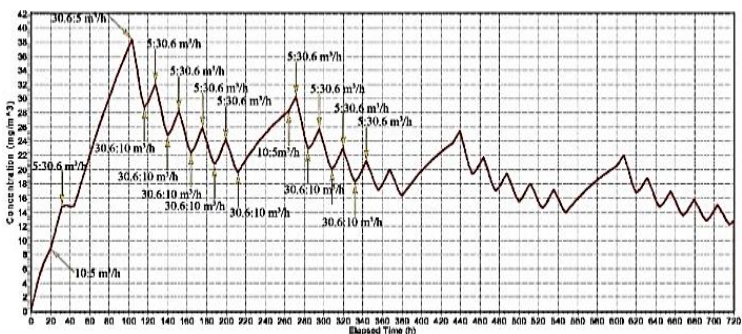

Figure 35: Predicted TVOC concentrations with different air change rates At Z1-B3

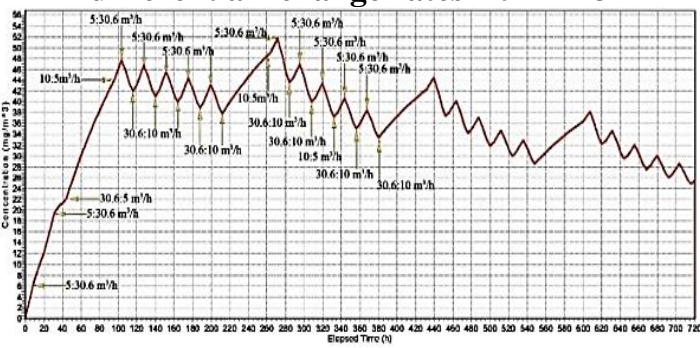

Figure 36: Predicted TVOC concentrations with different air change rates At Z2-B3

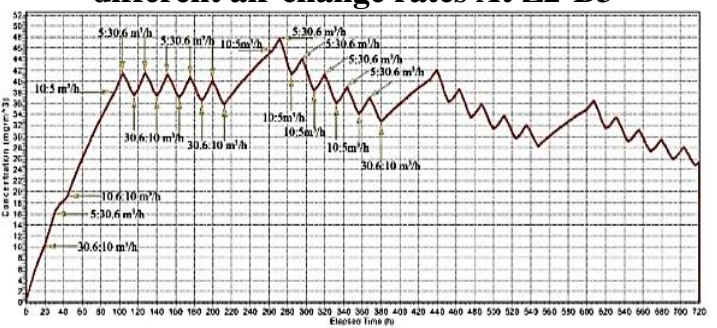

Figure 37: Predicted TVOC concentrations with different air change rates At Z3-B3

As shown in figures above, in oracle building's zones the changes of TVOCs concentration associated with the change of ventilation rates among the day all the month.

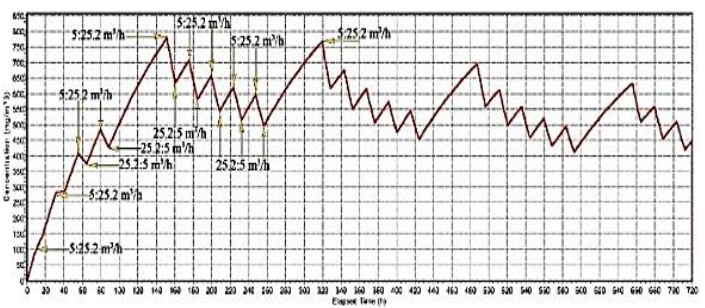

Figure 38: Predicted TVOC concentrations with different air change rates At Z1-PCC

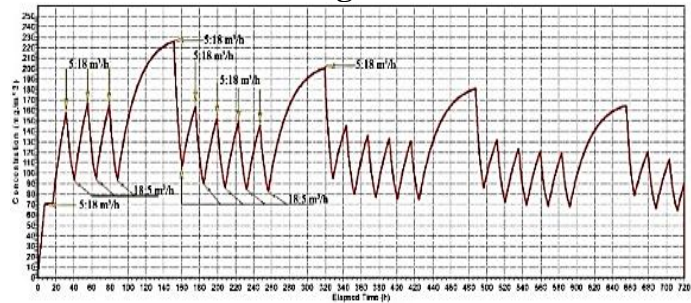

Figure 39: Predicted TVOC concentrations with different air change rates At Z2-PCC

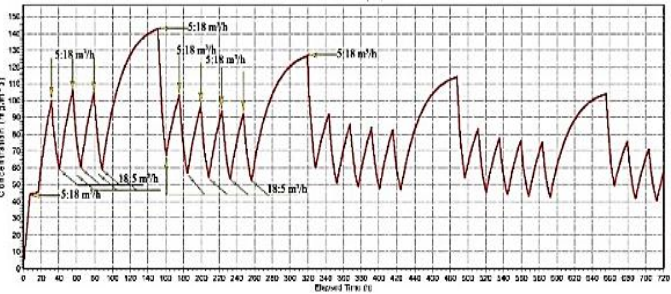

Figure 40: Predicted TVOC concentrations with different air change rates At Z3-PCC

As shown in figures above, in chamber of commerce building's zones the changes of TVOCs concentration associated with the change of ventilation rates among the day all the month, low ventilation rates associated with high concentration while higher ventilation rates associated with lower concentration.

\section{B. Natural ventilation:}

With natural ventilation the concentration of TVOC was low and acceptable, that means natural ventilation dilute indoor contaminants and reduce its concentration.

\subsubsection{Moisture:}

In oracle building Fungi appeared in internal building corners especially in basement because the internal parts of the walls near the corners lose heat through two outside walls, but certain points away from corners lose heat to outside through a single interface, so the temperature of the internal surface is the lowest at the internal corner lines. While in chamber of commerce building no moisture observed although it's located in humid weather this related to marble is coating building facades.

\subsubsection{Concentration of contaminants:}

As discussed previously, headache, lethargy, fatigue, and poor concentration were the most prevalent symptoms that major participated occupants suffer from, then came eye, throat troubles and skin symptoms. As mentioned in chapter one, the reasons of headache, lethargy, fatigue, and poor concentration were inadequate ventilation problems, insufficient fresh air, temperature, humidity, and high concentration of contaminants (e.g. formaldehyde, TVOCs, Benzene ...etc.) 
As shown in Figures below the Correlation between complains and maximum concentration of contaminants according to simulation results. Figure 41 show that high concentration of TVOCs in Oracle building and Chamber of commerce correlated with high percentage of complaints, while Figure 42 show that wasn't correlation between concentration of formaldehyde and complaints that's because of the low amount of wood used in chamber of commerce building. Figure 43 show that there is correlation between high concentration of benzene and toluene and high percentage of complaints in Oracle building and Chamber of commerce.

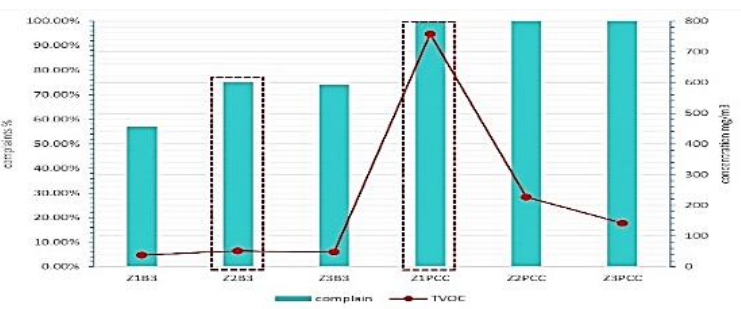

Figure 41: Correlation between complains and TVOCs maximum levels among 6 zones with mechanical ventilation

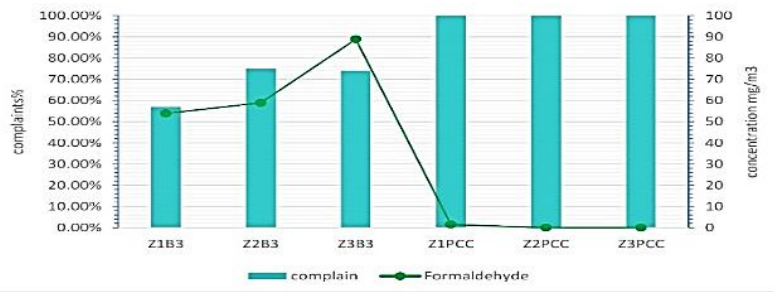

Figure 42: correlation between complains and Formaldehyde maximum levels among 6 zones with mechanical ventilation

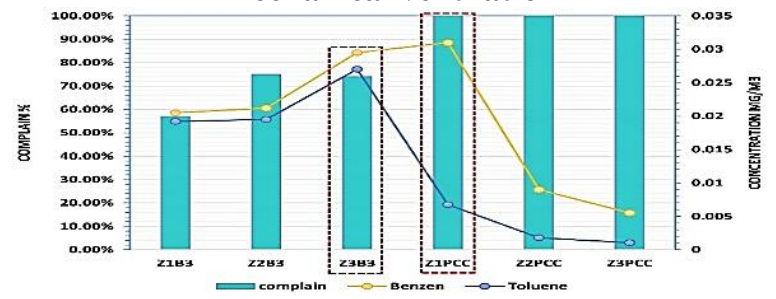

Figure 43: correlation between complains and (Benzene - Toluene) maximum levels among 6 zones with mechanical ventilation

\subsubsection{Lighting:}

In both buildings there were lighting problems, and occupants were dissatisfied of lighting.

Oracle building was better than chamber of commerce building in lighting because of using smart systems in artificial lighting and achieving design parameters of daylight.

\subsubsection{Materials:}

Furniture and finishing used in the two buildings are office unit, lockers, chairs, tables... made of wood that produces formaldehyde as a polluting gas, water-based wall paintings produce VOCs and toluene, gypsum board produce TVOCs and benzene, polypropylene carpets, concrete, brick and casual materials produce radon.

\subsubsection{Acoustics:}

In Oracle building, there were various Sound insulation types including envelope external walls and windows, polypropylene carpets, and false ceiling.

In addition, no clients deal with workers in work spaces, this makes workplace quite. Contrariwise, Chamber of Commerce building contains more noise because of dealing with clients, open windows near traffic roads and schools, also participated occupants show dissatisfaction of sound level in the building.

\section{Conclusion:}

SBS Symptoms were high at the first hours of the work days because ventilation problems caused by windows were closed or because of cleaning and maintenance activities or pollutants within the workspaces. There was strong correlation between ventilation rates and very high concentration of contaminants that cause high percentage of complaints.

Indoor air quality problems appeared as a result of low ventilation rates. The changes of TVOCs concentration associated with the change of ventilation rates, as low ventilation rates associated with high concentration while higher ventilation rates associated with lower concentration.

With natural ventilation the concentration of TVOC was low and acceptable, that means natural ventilation dilute indoor contaminants and reduce its concentration. The reasons of headache, lethargy, fatigue, and poor concentration were inadequate ventilation problems, insufficient fresh air, temperature, humidity, and high concentration of contaminants (e.g. formaldehyde, TVOCs, Benzene ...etc.) High concentration of TVOCs in Oracle building and Chamber of commerce correlated with high percentage of complaints There is correlation between high concentration of benzene and toluene and high percentage of complaints.

\section{REFERENCES:}

1. Rostron, J. (2005). Sick building syndrome: Concepts, issues and practice, Routledge.

2. Heimlich, J. E. (2003). Sick Building Syndrome. The Invisible Environment Fact Sheet Series. USA, the Ohio State University.

3. Spengler, J. D., et al. (2001). "Indoor air quality handbook."

4. Claude MOLINA, C. A. C. P., Ole VALBJBRN, Maurizio DE BORTOLI (1989). Sick Building Syndrome A Practical Guide. I. f. t. Environment.

5. EPA (2013). Moisture control does not require everything be kept completely dry. Moisture control is adequate as long as vulnerable materials are kept dry enough to avoid problems. E. P. Agency. USA.

6. GGHC (2007). Low Emitting Materials Technical Brief. E. a. Development. New York State, Green Guide for Health Care. 
7. Heinzerling, D., et al. (2013). "Indoor environmental quality assessment models: A literature review and a proposed weighting and classification scheme." Building and environment

8. Litti, G., et al. (2015). "Synthetic Scan and Simultaneous Index Aimed at the Indoor
Environmental Quality Evaluation and Certification for People and Artworks in Heritage Buildings." Energy Procedia 78: $1365-$ 1370 . 


\section{علاقة جودة البيئة الداخلية للمبنى و حدوث متلازمة المباني المريضة في المباني الادارية}

(الملخص:

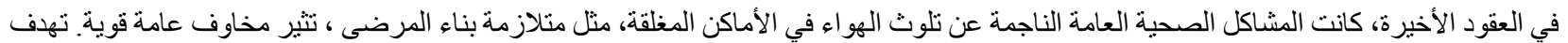

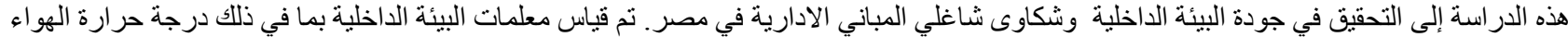

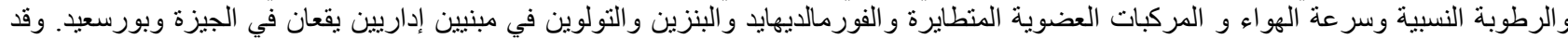

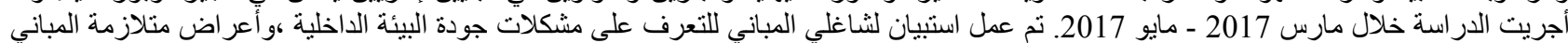
المريضة.

التركيز ات العالية للمركبات العضوية المتطايرة تؤثر على الصحة العامة. وقد تبين أن نو عية الهواء الداخلي قد تؤدي إلى أعر اض متلازمة المباني المريضة في المباني الادارية في مصرات للمركب. 